\title{
Chemical Diversity and Biological Activities of Meroterpenoids from Marine Derived-Fungi: A Comprehensive Update
}

\author{
Amr El-Demerdash ${ }^{1,2}\left(\mathbb{D}\right.$, Decha Kumla $^{3}{ }^{(0)}$ and Anake Kijjoa ${ }^{3, *(1)}$ \\ 1 The John Innes Centre, Department of Metabolic Biology, Norwich Research Park, Norwich NR4 7UH, UK; \\ eldemerdash555@gmail.com \\ 2 Chemistry Department, Faculty of Science, Mansoura University, Mansoura 35516, Egypt \\ 3 ICBAS-Instituto de Ciências Biomédicas Abel Salazar \& CIIMAR, Universidade do Porto, Rua de Jorge \\ Viterbo Ferreira 228, 4050-313 Porto, Portugal; Decha1987@hotmail.com \\ * Correspondence: ankijjoa@icbas.up.pt; Tel.: +351-2204-28331; Fax: +351-2206-2232
}

Received: 2 May 2020; Accepted: 12 June 2020; Published: 15 June 2020

\begin{abstract}
Meroterpenoids are a class of hybrid natural products, partially derived from a mixed terpenoid pathway. They possess remarkable structural features and relevant biological and pharmacological activities. Marine-derived fungi are a rich source of meroterpenoids featuring structural diversity varying from simple to complex molecular architectures. A combination of a structural variability and their myriad of bioactivities makes meroterpenoids an interesting class of naturally occurring compounds for chemical and pharmacological investigation. In this review, a comprehensive literature survey covering the period of 2009-2019, with 86 references, is presented focusing on chemistry and biological activities of various classes of meroterpenoids isolated from fungi obtained from different marine hosts and environments.
\end{abstract}

Keywords: meroterpenoids; marine-derived fungi; biological activities; antibacterial; cytotoxicity; anti-inflammatory

\section{Introduction}

Meroterpenoids are a large group of secondary metabolites of mixed biosynthetic origin, partially derived from mevalonate pathways. Another part of these metabolites can be derived from other biosynthetic pathways, most of which are polyketides and, to a lesser extent, nonpolyketides such as amino acids [1]. Meroterpenoids are widespread in nature, being isolated from terrestrial plants [2], marine invertebrates [3], and microorganisms such as fungi [4] and bacteria [5,6]. Fungi not only are the most prolific producers of meroterpenoids but also synthesize structurally diverse metabolites of this group with a wide range of biological and pharmacological activities [4]. Consistently, Geris and Simpson [4] published the first review of meroterpenoids produced by fungi in 2009, covering the period of 1968 to August 2008. This review provided information on isolation, structure elucidation and some biological activities, in addition to a detailed discussion of biosynthetic studies of 333 fungal meroterpenoids. However, in most cases, there was no indication if the fungi under study were from terrestrial or marine origin. In 2016, Matsuda and Abe published a comprehensive review of the biosynthesis of fungal meroterpenoids, updating the biosynthetic information previously discussed in the review by Geris and Simpson by summarizing the molecular basis, elucidated by modern techniques, of various classes of meroterpenoids [1]. On the other hand, it is interesting to note that despite the discovery of cephalosporins from the marine-derived fungus Cephalosporium acremonium (which is known today as Acremonium chrysogenum) in 1948 [7], the interest in the investigation of secondary metabolites from marine-derived fungi only started in the 90 s, with only 15 marine fungal 
metabolites reported by 1992 [8]. However, with the renewed interest in fungal biodiversity of the marine environment, the number of the isolated compounds kept rising to 270 in 2002 [9], and ramped up to 690 during the period of 2006 to mid-2010 [10]. From the literature search, it is evident that meroterpenoids constitute an important class of structurally unique secondary metabolites with relevant biological and pharmacological activities produced by fungi from nearly every possible marine habitat including soil and sediments, marine invertebrates (e.g., sponges, corals, sea cucumbers), marine plants (e.g., algae, sea glass, mangroves), and marine vertebrates (fishes) [11]. Moreover, they also display a myriad of biological activities including antioxidant [12], cytotoxic [13-15], antimicrobial [16,17], antiviral [18,19], anti-inflammatory [20], and anti-Alzheimer [21]. Despite this extraordinary increase in the research on natural products from marine-derived fungi, there is no systematic review of meroterpenoids from marine-derived fungi to date. Therefore, this review focuses on the chemistry and relevant biological activities of 320 meroterpenoids from marine-derived fungi reported in the literature over the period of 2009 to December 2019. Contrary to the classification based on the types of polyketides adopted by Geris and Simpson [4], herein we grouped the reported meroterpenoids according to the terpenoid classes, i.e., hemiterpenes, monoterpenes, sesquiterpenes and diterpenes. In this review, the biosynthesis aspects of this class of compounds are not discussed as they have been extensively reviewed by Geris and Simpson [4] and then updated by Matsuda and Abe [1].

\section{Chemistry and Biology of Meroterpenoids Isolated from Marine-Derived Fungi}

In this section, a comprehensive summary of 320 structurally diverse meroterpenoids isolated from the culture extracts of marine-derived fungi over the period of January 2009 to December 2019 is presented. All the isolated compounds were classified according to their featured terpenoid part, i.e., hemiterpenes, monoterpenes, sesquiterpenes and diterpenes. The relevant biological and pharmacological activities of the reported compounds are provided wherever applicable.

\subsection{Merohemiterpenoids}

\subsubsection{Merohemiterpenoids Containing Acyclic Hemiterpenes (Figure 1)}

Six merohemiterpenes (Figure 1), acremine A (1), acremine F (2), 5-choloroacremine A (3), 5-choloroacremine $\mathrm{H}(4)$, 9-O-methylacremine $\mathrm{F}(5)$ and 1-epi-acremine $\mathrm{F}(6)$, were obtained from the culture of the marine-derived fungus Acremonium persicinum, which was isolated from the marine sponge Anomoianthella rubra. None of the isolated compounds were assayed for any biological activity [22]. Mycophenolic-acid-based merohemiterpenes 7-17 (Figure 1) were isolated from Penicillium bialowiezense, which was obtained from the soft coral Sarcophyton subviride. Compounds 7-17 exhibited an inhibitory activity against inosine-50-monophosphate dehydrogenase (IMPDH2) with IC $_{50}$ values ranging from 0.59 to $24.68 \mu \mathrm{M}$. These compounds were also assayed for the in vitro immunosuppressive activity against the proliferation of T-lymphocytes, and 7-9 exhibited $\mathrm{IC}_{50}$ values ranging from 0.84 to $0.95 \mu \mathrm{M}$, whereas the $\mathrm{IC}_{50}$ values of $\mathbf{1 0 - 1 7}$ were from 3.27 to $24.68 \mu \mathrm{M}$ [23]. 
<smiles>CC(C)(O)/C=C/C1=CC(=O)[C@](C)(O)C[C@H]1O</smiles>

1<smiles>CC(C)(O)/C=C/C1=C[C@H](O)[C@@](C)(O)C[C@H]1O</smiles>

2

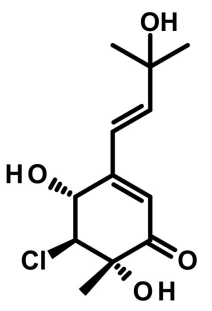

3<smiles>CC(C)(O)C1OC1C1=CC(=O)[C@](C)(O)[C@H](Cl)[C@H]1O</smiles>

4

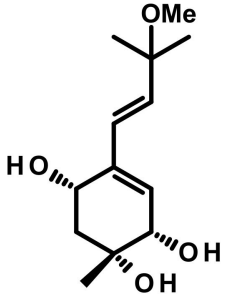<smiles>[R]Cc1c2c(c(O)c(C/C=C(\C)CCC(=O)O)c1OC)C(=O)OC2</smiles><smiles>[R2]C(=O)CC/C(C)=C/Cc1c(O)c2c(c(C)c1OC)C([R])OC2=O</smiles><smiles>COc1c(C)c2c(c(O)c1CC[C@H](C)C(=O)O)C(=O)OC2</smiles>

11<smiles>COc1c(C)c2c(c(O)c1C/C=C(\C)CCC(=O)OCC(O)CO)C(=O)OC2</smiles>

12<smiles>[R]C(=O)CC/C(C)=C/Cc1c(O)c(C)c2c(c1OC)C(=O)OC2</smiles><smiles>COc1c(C)c2c(c(O)c1C/C=C(\C)CCC(=O)NCCCC(=O)O)C(=O)OC2</smiles>

13

Figure 1. Chemical structures of acyclic merohemiterpenes 1-17.

\subsubsection{Merohemiterpenes Containing Cyclic Hemiterpenes (Figure 2)}

Spiroarthrinols A (18) and B (19) (Figure 2) were isolated from the sponge-derived fungus Arthrinium sp., obtained from the inner tissues of a marine sponge Sarcotragus muscarum collected off the coast of Southern Turkey. Both compounds did not show any significant in vitro cytotoxic activity against the Caco-2 (human epithelial colorectal adenocarcinoma) cell line [24]. A bicyclic merohemiterpene, acremine S (20) (Figure 2), was recently isolated from the marine-derived fungus Acremonium persicinum KUFA 1007 which was isolated from the marine sponge Mycale sp., collected from the coral reef in the Gulf of Thailand. Although 20 exhibited a weak inhibitory activity against acetylcholinesterase (AChE), its activity against butyrylcholinesterase (BuChE) was threefold higher than that of the positive control galantamine [25]. Acremines N (21), O (22), P (23) Q (24), R (25), spiroacremines A (26) and B (27) and 5-chlorospiroacremine (28) (Figure 2) were isolated from the marine-derived fungus Acremonium persicinum, obtained from a marine sponge Anomoianthella rubra. However, no bioactivity of the isolated compounds was investigated [22]. 

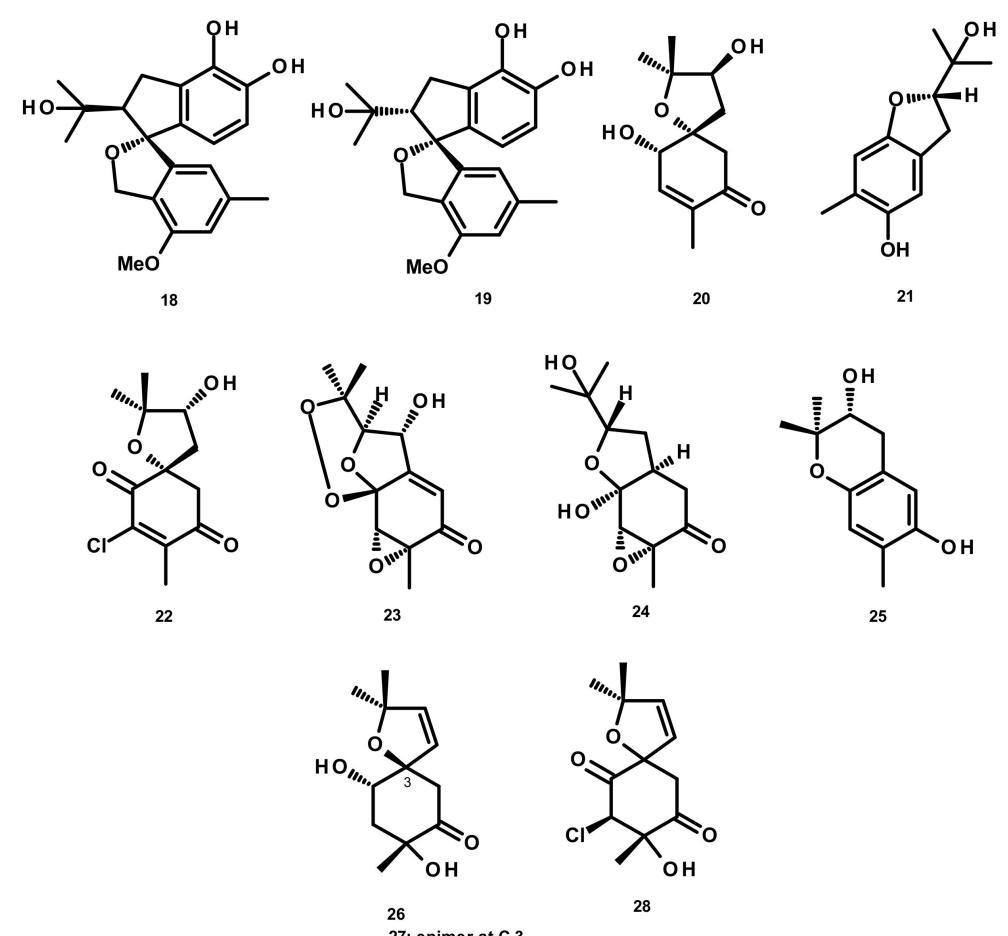

25

Figure 2. Chemical structures of cyclic hemiterpenes 18-28.

\subsection{Meromonoterpenoids (Figure 3)}

Chemical investigation of the endophytic fungus A1, isolated from leaves of the mangrove plant Scyphiphora hydrophyllacea, afforded the previously unreported guignardones F-I (29-32), together with the previously described guignardones A (33) and B (34) (Figure 3). Compound 32 displayed antibacterial activity against methicillin-resistant Staphylococcus aureus (MRSA) and S. aureus with inhibition zones of 9.0 and $11.0 \mathrm{~mm}$, respectively, whereas 34 exhibited inhibition activity against MRSA with a minimum inhibitory concentration (MIC) value of $65 \mu \mathrm{M}$ [26]. The previously unreported guignardones J (35), K (36), M (37) (Figure 3), along with 31, 33 and 34, were obtained from the culture extract of the endophytic fungus Aspergillus flavipes AIL8, which was isolated from the inner leaves of the mangrove plant Acanthus ilicifolius. The isolated compounds showed neither antibacterial nor cytotoxic activities [27].

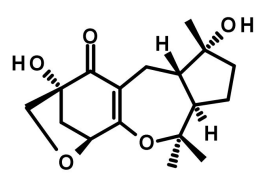

28<smiles>CO[C@H]1CC(O)C2=C(C[C@H]3[C@H](C(C)(C)O)CC[C@@]3(C)O2)C1=O</smiles>

31<smiles>CO[C@@H]1C[C@@H](O)C2=C(C[C@@H]3[C@@H](C(C)=O)CC[C@]3(C)O2)C1=O</smiles>

34<smiles>C=C(C)[C@H]1CC[C@@]2(C)OC3=C(C[C@H]12)C(=O)C(O)CC3O</smiles><smiles>C=C(C)[C@H]1CC[C@]2(C)OC3=C(C[C@H]12)C(=O)[C@]1(O)CO[C@H]3O1</smiles>

32<smiles>C=C(C)[C@@H]1CC[C@]2(C)OC3=C(C[C@H]12)C(=O)[C@H](OC)CC3O</smiles><smiles>CC(C)(O)[C@H]1CC[C@@]2(C)OC3=C(C[C@H]12)C(=O)[C@]1(O)COC3C1</smiles>

33<smiles>C=C(C)C1CCC2(C)OC3=C(CC12)C(=O)[C@H](O)CC3O</smiles>

36

Figure 3. Chemical structures of meromonoterpenoids 29-37. 


\subsection{Merosesquiterpenoids}

\subsubsection{Merosesquiterpenenoids Containing Acyclic Sesquiterpenes (Figures 4 and 5)}

Merosesquiterpenes 38-47 (Figure 4) were isolated from the marine-derived fungus Alternaria sp. JJY-32, which was obtained from the marine sponge Callyspongia sp. Supplementation experiments with specific enzyme inhibitors and putative precursors led to the conclusion that they are originated from a shikimate-isoprenoid hybrid biosynthetic pathway. All the compounds, except 44, displayed NF- $\mathrm{KB}$ inhibitory activities with $\mathrm{IC}_{50}$ values ranging from 39 to $85 \mu \mathrm{M}$ in RAW264.7 cells [28]. Another merosesquiterpene named arisugacin I (48) (Figure 4), was obtained from the endophytic fungus Penicillium sp. SXH-65, which was isolated from the leave of Tamarix chinensis growing on a saline-alkaline soil on the coast of Laizhou Bay in Dongying, China. Compound 48 showed no cytotoxicity against HL-60 (human leukemia), K562 (chronic myelogenous leukemia) and Hela (cervix carcinoma) cells [29]. 7-Deacetoxyyanuthone A (49), 2,3-hydrodeacetoxyyanuthone A (50), 22-deacetylyanuthone A (51) (Figure 4), three merosesquiterpenes featuring a quinone/hydroquinone scaffold, were isolated from the marine-derived fungus Gliomastix sp. ZSDS1-F7, obtained from the marine sponge Phakellia fusca Thiele, which was collected on the Yongxing island of Xisha. Compound 50 displayed significant in vitro cytotoxicity against several cancer cell lines including K562, MCF-7 (breast cancer), Hela, DU145 (prostate cancer), U937 (myeloid leukaemia), H1975 (nonsmall lung cancer), SGC-7901 (gastric cancer), A549 (lung carcinoma), MOLT-4 (acute lymphoblastic leukemia) and HL-60, with $\mathrm{IC}_{50}$ values ranging from 0.19 to $35.4 \mu \mathrm{M}$. Moreover, 49 displayed a moderate antitubercular activity with an $\mathrm{IC}_{50}$ value of $17.5 \mu \mathrm{M}$ [30].
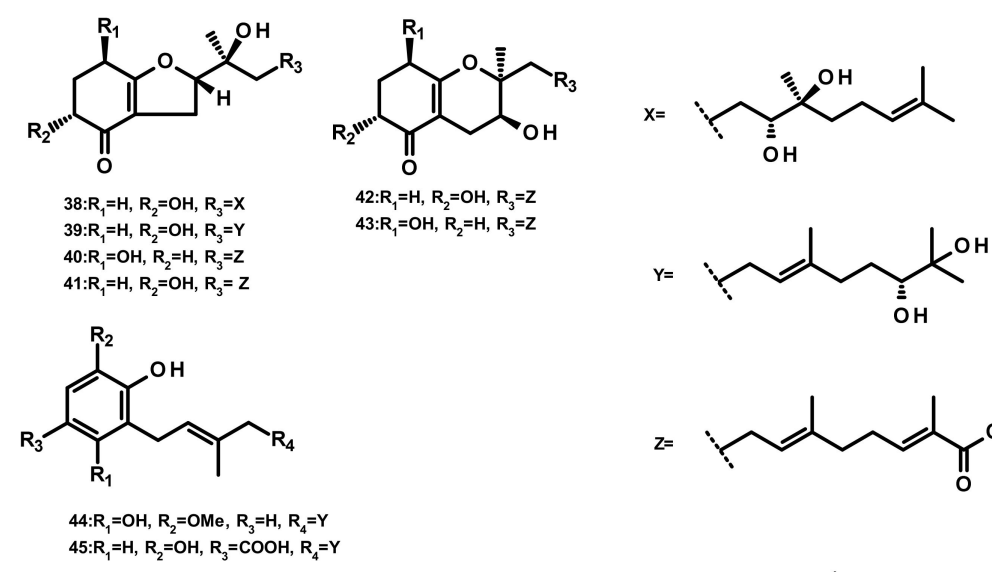<smiles>[R]C/C(C)=C/CC/C(C)=C/CC1=C(O)[C@@H](O)C[C@H](C)C1=O</smiles><smiles>C/C(=C\C/C=C(\C)CCC(O)C(C)(C)O)C/C=C/C(=O)c1c(O)cc(-c2ccc(O[N+](=O)[O-])cc2)oc1=O</smiles><smiles>CCC/C=C(\C)CC/C=C(\C)C(=O)O</smiles>

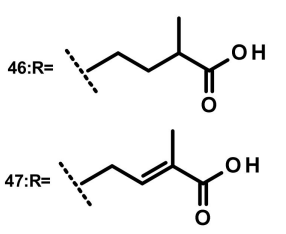<smiles>[2H]CC1=CC(=O)C(C/C=C(\C)CC/C=C(\C)CCC=C(C)C)OC1O</smiles>

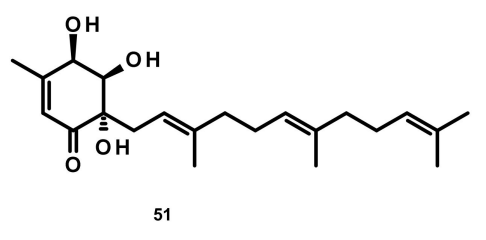

Figure 4. Chemical structures of acyclic sesquiterpenes 38-51. 
<smiles>C/C(=C\Cc1c(O)cc(O)c2c1C[C@@H](C)OC2=O)CCP</smiles><smiles>CCC(C)(O)[C@@]1(C)CCC(C(C)(C)O)O1</smiles><smiles>CCC(C)C(C)(O)C1CCC(C(C)(C)O)O1</smiles><smiles>CC(C)=CCCC(O)C(C)(C)O</smiles><smiles>CC(=CCc1c(O)c(C)c2c(c1O)C(=O)OC2)CCC=C(C)CCCC(C)(C)O</smiles><smiles>CC(C)=CCC/C(C)=C/CC/C(C)=C/Cc1c(O)c(C)c2c(c1O)C(=O)OC2</smiles><smiles>CC(=O)[C@H]1[C@@H]2O[C@@]1(C/C=C(\C)CC/C=C(\C)CCC(=O)O)C(=O)C=C2C</smiles><smiles>CC(=CCCC(=O)O)CCC=C(C)CCC(=O)O</smiles><smiles>CC1=CC(=O)[C@@](O)(C/C=C(\C)CC/C=C(\C)CCC(=O)O)[C@@H](O)[C@@H]1O</smiles>

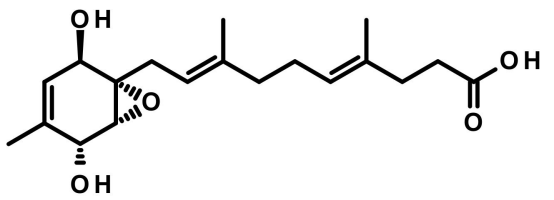

58

59

Figure 5. Chemical structures of acyclic sesquiterpenes 52-60.

Verruculides $B_{2}$ (52), $B_{3}(53)$ and $B(54)$ (Figure 5) were isolated from the fungus Penicillium sp. SCS-KFD09 which was obtained from a marine worm, Sipunculus nudus. Compound $\mathbf{5 2}$ showed weak antibacterial activity against $S$. aureus, with a MIC value of $32 \mu \mathrm{g} / \mathrm{mL}$ [31]. A farnesyl phthalide derivative $\mathbf{5 5} \mathbf{a}$ and its previously reported analogue $\mathbf{5 5 b}$ (Figure 5) were isolated from the marine sediment-derived fungus Penicillium rudallense. Compound 55a did not significantly suppress receptor activator of nuclear factor $\mathrm{kB}$ ligand (RANKL)-induced osteoclast differentiation [32]. Five farnesylcyclohexenone derivatives, peniginsengins A-E (56-60) (Figure 5), were isolated from the culture extract of Penicillium sp. YPGA11 which was obtained from deep-sea water at a depth of $4500 \mathrm{~m}$ in the Yap Trench (West Pacific Ocean). The absolute configurations of their stereogenic carbons were established by comparison of the calculated and experimental electronic circular dichroism (ECD) spectra. Compounds 57-60 displayed weak to moderate antibacterial activity against $S$. aureus ATCC 25,913 and S. aureus ATCC 43,300 with MIC values of $8-32 \mu \mathrm{g} / \mathrm{mL}$ [33].

\subsubsection{Meroterpenoids Containing Monocyclic Sesquiterpenes (Figure 6)}

Merosesquiterpenes containing a cyclopentane ring 61-65 (Figure 6) were obtained from Alternaria sp. JJY-32, which was isolated from the marine sponge Callyspongia sp. A shikimate-isoprenoid hybrid biosynthetic pathway for these compounds were proposed based on supplementation experiments with specific enzyme inhibitors and putative precursors. Compounds 61-65 displayed NF- $\mathrm{kB}$ inhibitory activities, in RAW264.7 cells, with $\mathrm{IC}_{50}$ values of $52,76,75,50$ and $39 \mu \mathrm{M}$, respectively [28]. Guignardone $\mathrm{L}$ (66) (Figure 6), also reported from the mangrove endophytic fungus $A$. flavipes, showed no significant antibacterial or cytotoxic activities [27]. Chemical examination of the culture extract of Alternaria alternata ICD5-11, which was obtained from a marine isopod Ligia exotica, led to the isolation of the previously described tricycloalternarene acid 11a (TCA 11a, 67) and two previously unreported 
tricycloalternarenes K (68) and L (69) (Figure 6). Compounds 68 and 69 displayed no antibacterial activity against Bacillus subtilis and $S$. aureus by the disk diffusion method at a concentration of $20 \mu \mathrm{g} /$ disk [34].<smiles>CC(C)=CCC[C@H](C)[C@H]1CC[C@@](C)(O)[C@]12CC1=C(O[C@H](O)CC1)[C@H]2O</smiles><smiles>[R][C@H]1C[C@@H](O)C2=C(C[C@H]3[C@H](C(C)(O)CCC=C(C)C)CC[C@@]3(C)O2)C1=O</smiles>

61 62: $R=O M e(4 S)$ 63:R=H (4R)<smiles>[R]C(C)=CCC[C@@H](C)C1=CC[C@]2(C)OC3=C(C[C@H]12)C(=O)[C@H](O)CC3</smiles><smiles>CO[C@H]1C[C@@H](O)C2=C(C[C@H]3[C@@H](/C(C)=C/C=C/C(C)=O)CC[C@]3(C)O2)C1=O</smiles><smiles>C/C(=C\CCC(C)C1=CC[C@]2(C)OC3=C(C[C@H]12)C(=O)CC[C@H]3O)C(=O)O</smiles>

67<smiles>CC(CCCC(C)C1=CC[C@]2(C)OC3=C(C[C@H]12)C(=O)CC[C@H]3O)C(=O)O</smiles>

68<smiles>CC(CCC(=O)O)C1=CC[C@]2(C)OC3=C(C[C@H]12)C(=O)CC[C@H]3O</smiles>

69

Figure 6. Chemical structures of monocyclic sesquiterpenes 61-69.

\subsubsection{Meroterpenoids Containing Bicyclic Sesquiterpenes}

Drimane Sesquiterpenes Linked to a 2-pyrone (Figure 7)

Asperdemin (70) (Figure 7), a bicyclic merosesquiterpene, was isolated from the culture extract of the marine fungus Aspergillus versicolor, isolated from benthos of the Sakhalin Bay. Compound 70 displayed weak cytostatic and membranolytic activities in developing embryos of the sea urchin Strongylocentrotus nudus at a concentration of $6.38 \mathrm{mmol} / \mathrm{L}$, and also induced haemolysis of human erythrocytes with an $\mathrm{EC}_{50}=1.15 \mathrm{mmol} / \mathrm{L}$ [35]. Asperversins $\mathrm{A}(\mathbf{7 1})$ and $\mathrm{B}$ (72), merosesquiterpenes possessing a 5/6/6/6 ring system, and their analogues asperversins $C-G$ (73-77) (Figure 7) featuring a 7/6/6/6 cyclic ring system, were isolated together with 70, from the marine-derived fungus Aspergillus versicolor, isolated from the mud of the South China Sea. Compounds 70-77 exhibited neither cytotoxicity against A549, MCF-7, HepG2 (hepatocellular carcinoma) and HL-60 cell lines nor antibacterial activity against methicillin-resistant S. aureus (MRSA), methicillin-sensitive S. aureus (MSSA), Escherichia coli and Pseudomonas aeruginosa. Compounds 70-77 were also assayed for their AChE inhibitory activity; however only 77 showed a strong inhibitory activity with an $\mathrm{IC}_{50}$ value of $13.6 \mu \mathrm{M}$ whereas the rest of the compounds was inactive at a concentration as high as $40 \mu \mathrm{M}$ [36]. 


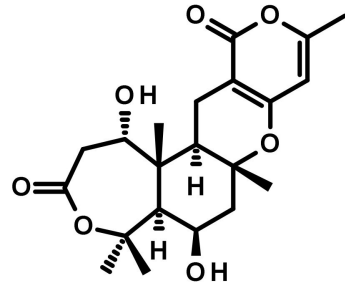

70

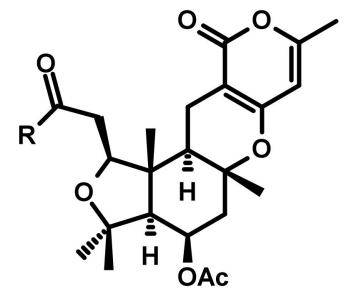

71:R=OMe

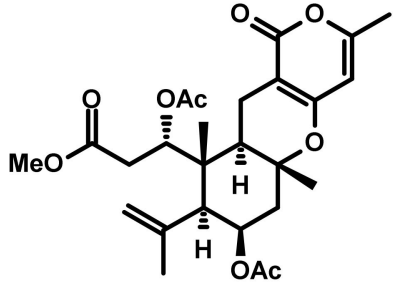

73

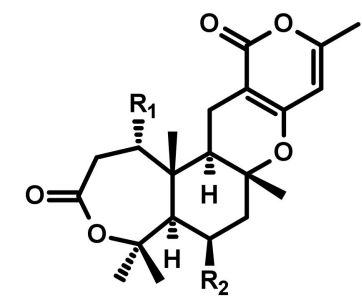

74: $\mathrm{R}_{1}=\mathrm{OH}, \mathrm{R}_{2}=\mathrm{H}$ $75: R_{1}=O H, R_{2}=O A C$ $76: R_{1}=R_{2}=O A C$

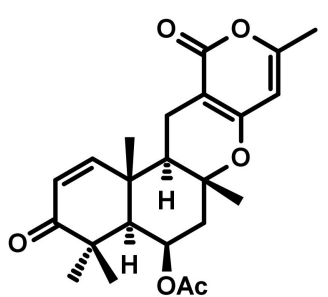

77

Figure 7. Chemical structures 70-77.

Drimane Sesquiterpenes Linked to a Phenyl 2-pyrone (Figure 8)

Three merosesquiterpenes containing a phenyl $\alpha$-pyrone, arigsugacin I (78), arigsugacin $F(79)$ and territrem B (80) (Figure 8), were isolated from the endophytic fungus Penicillium sp. sk5GW1L, which was obtained from the leaves of the mangrove plant Kandelia candel. Compounds 78-80 displayed a potent in vitro inhibitory activity against $\mathrm{AChE}$, with $\mathrm{IC}_{50}$ values of $0.64 \pm 0.08 \mu \mathrm{M}, 0.37 \pm 0.11 \mu \mathrm{M}$, and $7.03 \pm 0.20 \mathrm{nM}$, respectively [37]. Another merosesquiterpene containing a phenyl $\alpha$-pyrone, S14-95 (81) (Figure 8), was obtained from the marine sponge-associated fungus Aspergillus similanensis KUFA 0013, which was isolated from the marine sponge Rhabdermia sp. Compound $\mathbf{8 1}$ was evaluated for its antimicrobial activities against a panel of Gram-positive (S. aureus ATCC 25,923 and B. subtilis ATCC 6633) and Gram-negative bacteria (E. coli ATCC 25,922 and P. aeruginosa ATCC 27,853) and yeast (Candida albicans ATCC 10,231); however no activities were observed (MIC > $256 \mu \mathrm{g} / \mathrm{mL}$ ) [38]. Arisugacin J (same as arigsugacin I, 78), arisugacin F (same as arigsugacin F, 79), arisugacin $G(82)$, arisugacin B (83), territrem C (84) (Figure 8) and territrem B (80) were obtained from the endophytic fungus Penicillium sp. SXH-65, which was isolated from the leave of Tamarix chinensis. Compounds 82 and 83 exhibited weak cytotoxicity toward HL-60, K562 and Hela cell lines with $\mathrm{IC}_{50}$ values of 24.2, 36.2, 59.9 and 45.9, 46.6, $44.4 \mu \mathrm{M}$, respectively [29]. Chemical examination of the mangrove-derived fungus Penicillium sp., isolated from the leaves of the mangrove plant Kandelia candel, yielded 3-epi-arigsugacin $\mathrm{E}(\mathbf{8 5})$ arisugacin D (86), terreulactone $C(87)$ (Figure 8) and the previously mentioned arisugacin $B$ (83) and territrem $C(\mathbf{8 4})$. Compounds 83-85 displayed potent AChE inhibitory activity with $\mathrm{IC}_{50}$ values of 3.03, 0.23 and $0.028 \mu \mathrm{M}$, respectively [39]. Ding et al. [40] reported the isolation of two previously unreported phenylpyropenes $\mathrm{E}(\mathbf{8 8})$ and $\mathrm{F}(\mathbf{8 9})$, together with the previously described phenylpyropenes B (90), C (91), and D (92) (Figure 8), from the culture of the marine-derived fungus Penicillium concentricum ZLQ-69 which was isolated from the water samples taken from the coast of the Bohai Sea in Binzhou, Shandong Province, China. Compounds 88-92 were assayed for their in vitro cytotoxicity against three human cancer cell lines, A549, MGC-803 (gastric cancer) and HL-60 by the MTT method. However, only $\mathbf{8 8}$ and $\mathbf{9 2}$ exhibited moderate cytotoxicity against the MGC-803 cell line with $\mathrm{IC}_{50}$ values of 19.1 and $13.6 \mu \mathrm{M}$, respectively. 


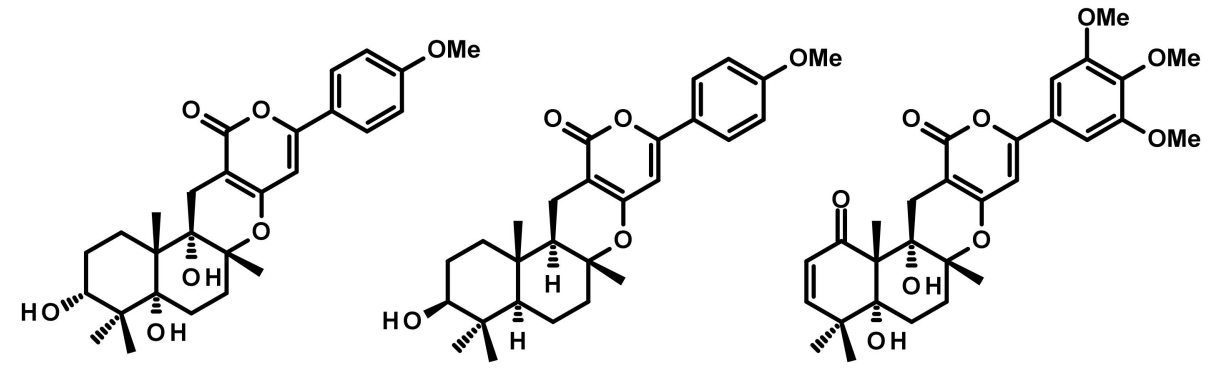

78

79

(c) 83: $R_{1}=R_{3}=H, R_{2}=O M e$
84: $R_{1}=R_{3}=O M e, R_{2}=O H$

80<smiles>CC(=O)O[C@H]1CC[C@@]2(C)[C@H](CC[C@@]3(C)Oc4cc(-c5ccccc5)oc(=O)c4C[C@H]23)C1(C)C</smiles>

81
82

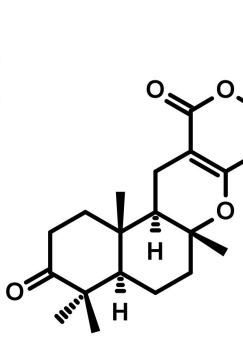

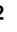

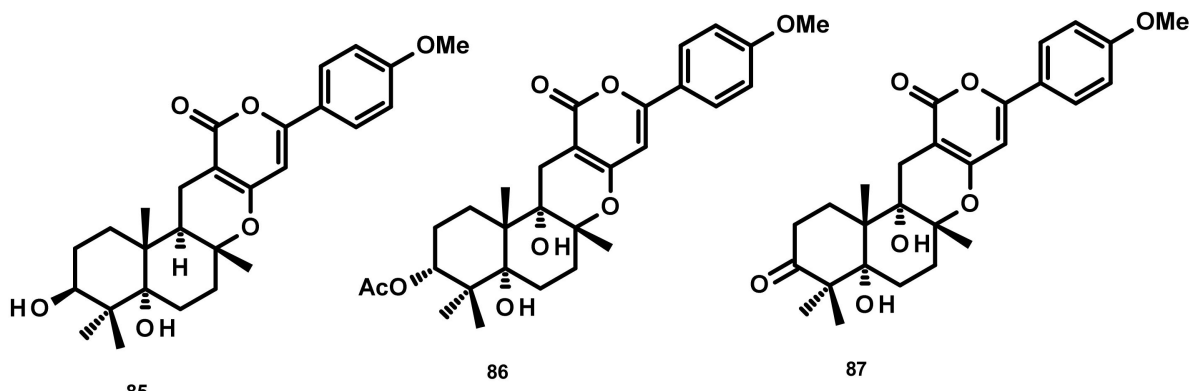

85

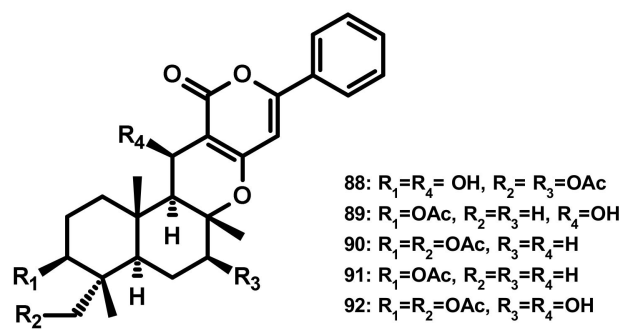

Figure 8. Chemical structures of 78-92.

\section{Pyripyropenes (Figure 9)}

Pyripyropenes S (93) and E (94), and the previously unreported pyripyropene T (95) (Figure 9) were isolated from the marine sponge-associated fungus Aspergillus similanensis KUFA 0013. Compounds 93, 94 and 95 showed neither antibacterial nor antifungal activities against a panel of Gram-positive (S. aureus ATCC 25,923 and B. subtilis ATCC 6633) and Gram-negative bacteria (E. coli ATCC 25,922 and P. aeruginosa ATCC 27,853) and yeast (C. albicans ATCC 10,231) with MIC > $256 \mu \mathrm{g} / \mathrm{mL}[38,41]$. Besides two previously unreported pyripyropene derivatives, 13-dehydroxy-1,11 deacetylpyripyropene A (96) and 1-deacetylpyripyropene A (97) (Figure 9), six previously described pyripyropenes, namely 94, 11-deacetylpyripyropene $\mathrm{O}$ (98), 7-deacetylpyripyropene A (99), pyripyropenes $\mathrm{O}(\mathbf{1 0 0})$ and $\mathrm{A}$ (101) and 13-dehydroxypyripyropene A (102) (Figure 9) were isolated from the marine-derived fungus Fusarium lateritium 2016F18-1, which was isolated from the marine sponge Phyllospongia foliascens. Compounds 98, 100 and 101 exhibited significant cytotoxicity against five human cancer cell lines, i.e., CNE1 (nasopharyngeal carcinoma), CNE2 (nasopharyngeal carcinoma), HONE1 (nasopharyngeal carcinoma), SUNE1 (spectrin repeat containing nuclear envelope protein 1), GLC82 (lung carcinoma) 
cancer cell lines as well as HL7702 (normal hepatic) cells [42]. Compounds 99, 101 and 102 were also isolated from the marine-derived fungus Neosartorya pseudofischeri which was obtained from the inner tissue of the starfish Acanthaster planci. Compounds 99, 101 and 102 exhibited significant cytotoxicity against $\mathrm{Sf} 9$ cells, highlighting them for a prospective platform for biorational pesticides development [43]. Compounds 94, 100, 101 and pyripyropene B (103) (Figure 9) were reported from the marine-derived fungus Penicillium concentricum ZLQ-69; however they were not assayed for any bioactivity [40].

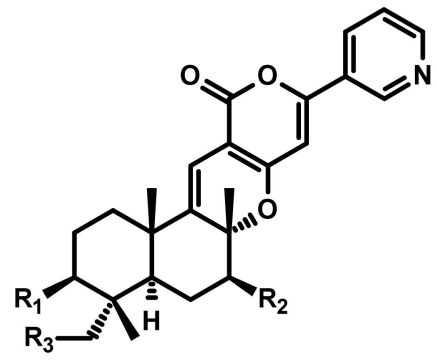

93: $R_{1}=R_{2}=R_{3}=O A C$

95: $R_{1}=R_{3}=O A c, R_{2}=O H$

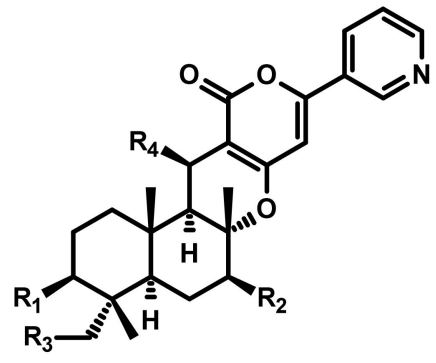

94: $R_{1}=O A C, R_{2}=R_{3}=R_{4}=H$ $96: R_{1}=R_{3}=O H, R_{2}=O A C, R_{4}=H$ $97: R_{1}=R_{4}=O H, R_{2}=R_{3}=O A C$ 98: $R_{1}=O A c, R_{2}=R_{4}=H, R_{3}=O H$ 99: $\mathrm{R}_{1}=\mathrm{R}_{3}=\mathrm{OAC}, \mathrm{R}_{2}=\mathrm{R}_{4}=\mathrm{OH}$ $100: R_{1}=R_{3}=O A c, R_{2}=R_{4}=H$ 101: $R_{1}=R_{2}=R_{3}=O A C, R_{4}=O H$ 102: $R_{1}=R_{2}=R_{3}=O A c, R_{4}=H$ 103: $\mathrm{R}_{1}=\mathrm{OCOCH}_{2} \mathrm{CH}_{3}, \mathrm{R}_{2}=\mathrm{R}_{3}=\mathrm{OAc}, \mathrm{R}_{4}=\mathrm{OH}$

Figure 9. Chemical structures of pyripyropenes 93-103.

Drimane Sesquiterpenes Linked to a 4-pyrone (Figure 10)

Penicillipyrones A (104) and B (105) (Figure 10), two merosesquiterpenes containing a 4-pyrone moiety, were isolated from the marine-derived fungus Penicillium sp. F446, which was obtained from marine sediments at the depth of $25 \mathrm{~m}$ collected from Geomun-do (Island), Korea. Compound 104 exhibited significant induction of quinone reductase in a dose-dependent manner in murine Hepa 1c1c7 (murine hepatoma) cells over the concentration range 5-40 $\mu \mathrm{M}$ [44].

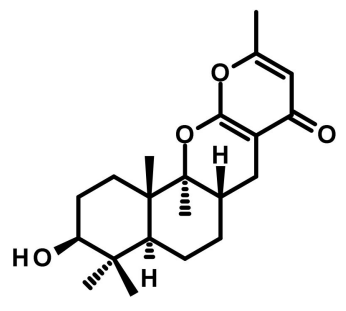

104

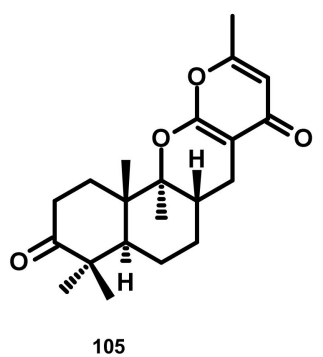

105

Figure 10. Chemical structures of 104 and 105.

Drimane Sesquiterpenes Linked to a Cyclohexanone Derivative by a Methylene Bridge (Microphorin-Related Compounds) (Figure 11)

Epoxyphomalins A (106) and B (107) (Figure 11) were isolated from the culture extract of the marine-derived fungus Paraconiothyrium cf. sporulosum (initially identified as Phoma sp. 193H12), obtained from the marine sponge Ectyplasia perox, which was collected from the Caribbean Sea. Compounds 106 and 107 displayed significant antiproliferative activity against a panel of 36 human tumour cell lines with $\mathrm{IC}_{50}$ values of 0.11 and $1.25 \mu \mathrm{g} / \mathrm{mL}$, respectively [45]. Further investigation 
of the same fungus by the same research group has resulted in the isolation of three new analogues which were named epoxyphomalins C (108), D (109) and E (110) (Figure 11). Compounds 108-110 were evaluated for their cytotoxicity against the same panel of 36 tumour cell lines. Although $\mathbf{1 0 8}$ and 110 were inactive at a concentration of $27.6 \mu \mathrm{M}, 109$ displayed a selective cytotoxicity, particularly against the prostate PC3M and bladder BXF $1218 \mathrm{~L}$ cancer cell lines with $\mathrm{IC}_{50}$ values of 0.72 and $1.43 \mu \mathrm{M}$, respectively [46]. Purpurogemutantin (111), macrophorin A (112) and 4'-oxomacrophorin (113) (Figure 11), three merosesquiterpenes featuring a quinone/hydroquinone scaffold, were isolated from the marine sponge-associated fungus Gliomastix sp. ZSDS1-F7, which was obtained from the marine sponge Phakellia fusca collected on the Yongxing island of Xisha, China. Compounds 111-113 showed significant in vitro cytotoxicity against various cancer cell lines including K562, MCF-7, Hela, DU145, U937, H1975, SGC-7901, A549, MOLT-4 and HL-60, with IC $_{50}$ values ranging from 0.19 to $35.4 \mu \mathrm{M}$. Moreover, $\mathbf{1 1 2}$ and $\mathbf{1 1 3}$ displayed a moderate antitubercular activity with $\mathrm{IC}_{50}$ values of 22.1 and $2.44 \mu \mathrm{M}$, respectively [30].

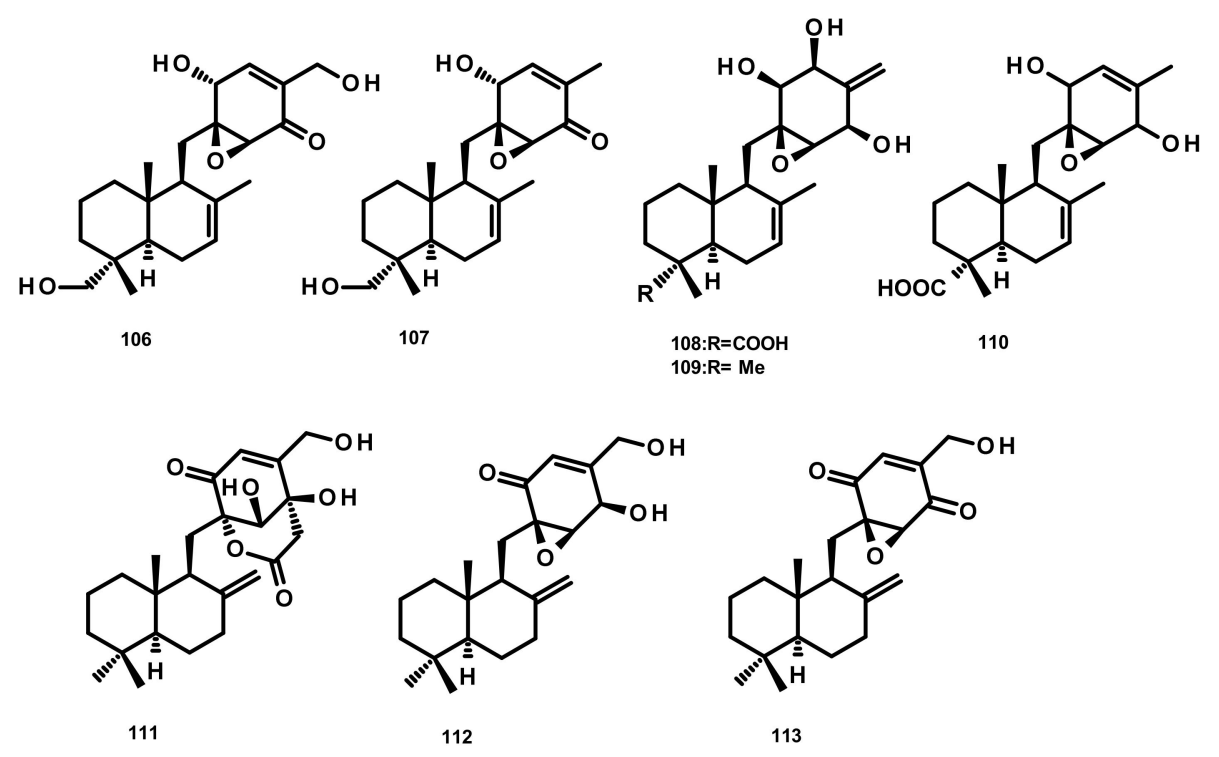

Figure 11. Chemical structures of 106-113.

Drimane Sesquiterpenes Linked to Spirobezopyran Derivatives (Figure 12)

Chermesins A-D (114-117) (Figure 12), three spiropyranoquinone drimanes, were isolated from the culture extract of the algicolous fungus Penicillium chermesinum EN-480 which was obtained from the marine red alga Pterocladiella tenuis. Compounds 114-117 were assayed for their antimicrobial activity against four human pathogenic bacteria (E. coli, Micrococcus luteus and P. aeruginosa) and yeast (C. albicans), five plant pathogenic fungi (Alternaria brassicae, Colletotrichum gloeosporioides, Fusarium oxysporum, Gaeumannomyces graminis, and Physalospora piricola) and five aquatic bacteria (Aeromonas hydrophila, Edwardsiella tarda, Vibrio alginolyticus, V. harveyi, and V. parahemolyticus). Compounds 114 and 115 were active against $C$. albicans, E. coli, $M$. luteus, and $V$. alginolyticus, with MIC values ranging from 8 to $64 \mu \mathrm{g} / \mathrm{mL}$, whereas 117 only showed weak activity against $E$. coli (MIC $=64 \mu \mathrm{g} / \mathrm{mL}$ ). Compound 116 exhibited no activity against all of the tested strains [47]. Chartarolides A-C (118-120) (Figure 12), another spirobenzopyran drimanes isolated from the fermentation broth of the marine-derived fungus Stachybotrys chartarum WGC-25C-6, which was obtained from the marine sponge Niphates recondite, exhibited significant cytotoxicity against a panel of human tumour cell lines including HCT-116 (colon carcinoma), HepG2, BGC-823 (gastric carcinoma), NCI-H1650 (nonsmall cell lung carcinoma), A2780 (ovarian carcinoma) and MCF-7, with $\mathrm{IC}_{50}$ values ranging from 1.4 to $12.5 \mu \mathrm{M}$. These compounds also exhibited durable inhibitory activities against four tumour-associated protein kinases, including FGFR3, IGF1R, PDGFRb and TrKB, with $\mathrm{IC}_{50}$ values ranging from 2.6 to $25 \mu \mathrm{M}$ [48]. 


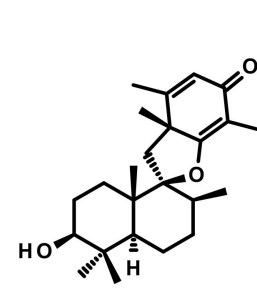

114

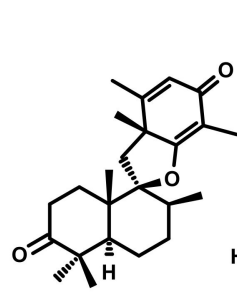

115

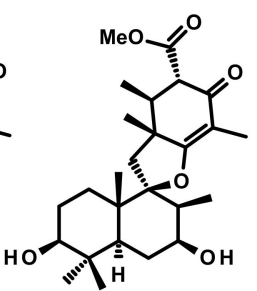

116

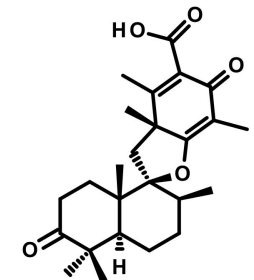

117

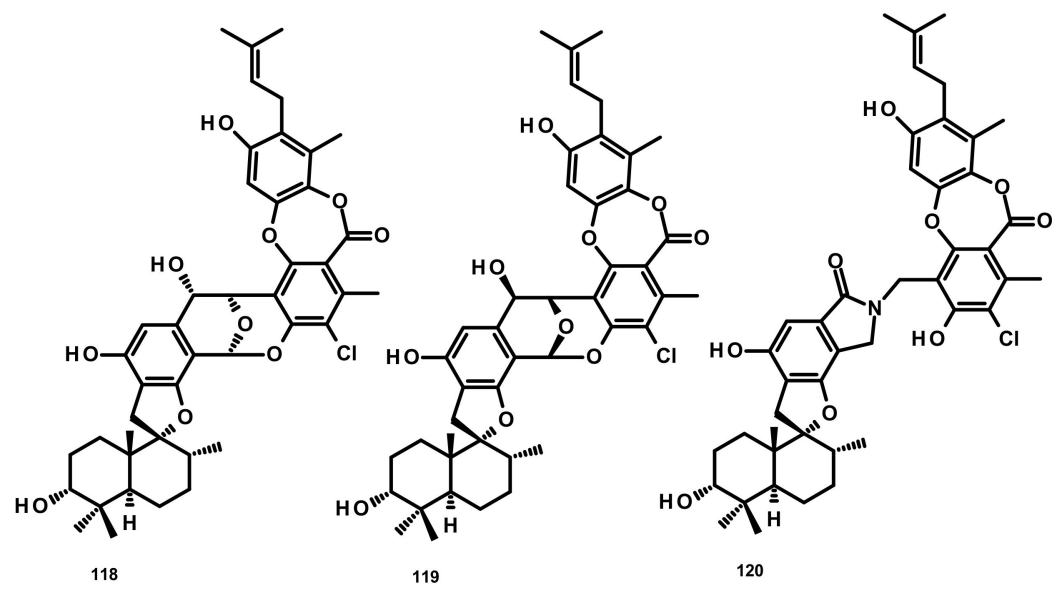

Figure 12. Chemical structures of 114-120.

Drimane Sesquiterpenes Linked to Isochromone Derivatives (Figures 13 and 14)

Ten isochromone-based drimanes, including chrodrimanins K (121), L (122), M (123), N (124), H (126), F (127), E (128), A (129) and B (130) and hydroxypentacecilide A (125) (Figure 13), were isolated from the fermentation broth of Penicillium sp. SCS-KFD09 which was obtained from a marine worm Sipunculus nudus. Compounds 121, 124 and $\mathbf{1 2 5}$ displayed weak antiviral activity against the influenza A virus (H1N1) with $\mathrm{IC}_{50}$ values of 74, 58, and $34 \mu \mathrm{M}$, respectively [31]. Compounds $\mathbf{1 2 9}$ and $\mathbf{1 3 0}$ were also isolated from the culture extract of the endophytic fungus Talaromyces amestolkiae YX1, obtained from healthy leaves of the mangrove tree Kandelia obovata, collected from Zhanjiang Mangrove Nature Reserve in Guangdong, China [20].

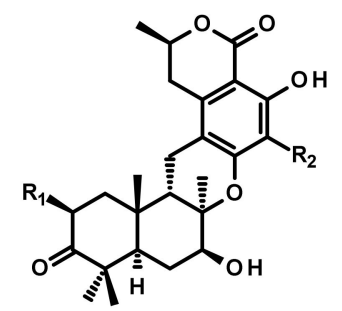

$121: R_{1}=H, R_{2}=C l$ $122: R_{1}=R_{2}=C l$ $126: R_{1}=R_{2}=H$

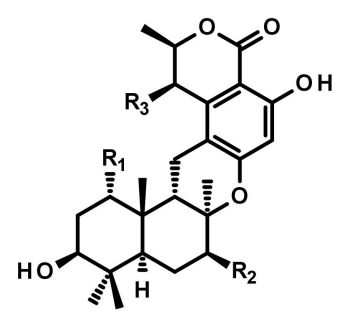

123: $R_{1}=R_{2}=O H, R_{3}=H$ 124: $\mathrm{R}_{1}=\mathrm{H}, \mathrm{R}_{2}=\mathrm{OH}, \mathrm{R}_{3}=\mathrm{OAC}$ $125: R_{1}=R_{2}=R_{3}=H$ $127: \mathrm{R}_{1}=\mathrm{R}_{3}=\mathrm{H}, \mathrm{R}_{2}=\mathrm{OH}$

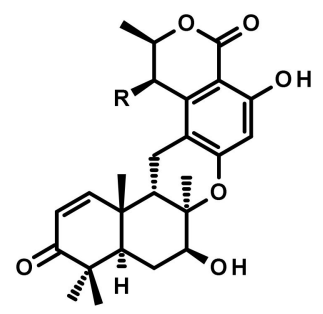

128: $\mathrm{R}=\mathrm{H}$ 129: $\mathrm{R}=\mathrm{OH}$
$130: \mathrm{R}=\mathrm{OAC}$

Figure 13. Chemical structures of 121-130.

Talaromyolides A-D (131-134) (Figure 14), analogs of seco-drimane linked to isochromone, were isolated from the marine-derived fungus Talaromyces sp. CX11, obtained from the red seaweed Grateloupia filicina. Compounds 131-134 displayed no cytotoxicity against a panel of human tumour cell lines including HL-60, K562, MGC-803, BEL-7402 (hepatocellular carcinoma), SH-SY5Y (neuroblastoma), HCT-116, MDA-MB-231 (triple negative breast cancer), A549, MCF-7/ADM (Adriamycin-resistant 
breast cancer), HO8910 (ovarian cancer), U87 (glioblastoma) and NCI-H1975 (nonsmall cell lung cancer). Interestingly, 134 exhibited potent antiviral activity against pseudorabies virus (PRV) with a $\mathrm{CC}_{50}$ value of $3.35 \mu \mathrm{M}[19]$.

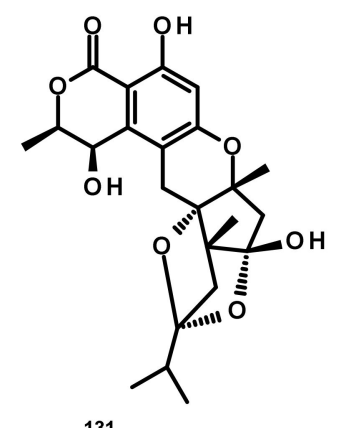

131

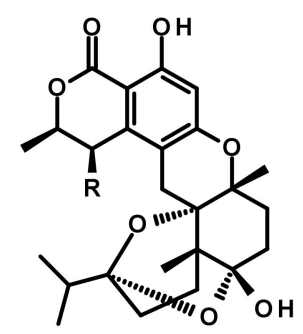

132: $\mathrm{R}=\mathrm{OH}$

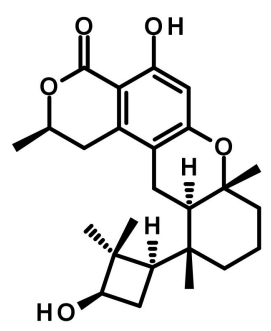

134

Figure 14. Chemical structures of 131-134.

Drimane Sesquiterpenes Linked to 5-Methylorsellinic Acid

Austalides (Figure 15)

Five austalides M-Q (135-139) (Figure 15) were isolated from the marine-derived fungus Aspergillus sp. which was obtained from the Mediterranean sponge Tethya aurantium. Compounds 135-139 were evaluated for their cytotoxic activity against the murine cancer cell line L5178Y by the MTT assay; however, none of them were active [49]. Australide $\mathrm{H}$ acid butyl ester (140), australide $\mathrm{H}$ acid (141), australide $P$ acid butyl ester (142), australide $P$ acid (143), australide $Q$ acid (144), 13-O-deacetylaustalide I (147) and 13-deacetoxyaustralide I (148) (Figure 15) were isolated from the culture extract of Penicillium thomii KMM 4645 whereas 141-144, 147, 148, 13-deoxyaustralide $Q$ acid (145), 17-O-demethylaustalide B (146) and 17S-dihydroaustalide K (149) (Figure 15) were isolated from the culture of P. lividum KMM 4645. Both of the fungal strains were isolated from the superficial mycobiota of the brown alga Sargassum miyabei, collected from the Sea of Japan [50]. Compounds 140, 141, 146, and 148 did not exhibit cytotoxicity against MDA-MB-231 and JB6 Cl41 (mouse epidermal) cell lines; however, these compounds inhibited AP-1-dependent transcriptional activity in JB6 Cl41 cell line at noncytotoxic concentrations after $12 \mathrm{~h}$ of treatment. Interestingly, these compounds showed significant inhibitory activity at a concentration of $6.25 \mu \mathrm{M}$ but did not reduce cell viability at $100 \mu \mathrm{M}$ [50]. Moreover, 140-144, 147, and 148 exhibited strong inhibitory activity against endo-1,3- $\beta$-D-glucanase, obtained from a crystalline stalk of the marine mollusk Pseudocardium sachalinensis [50]. The culture extract of the marine sponge-associated fungus Aspergillus aureolatus HDN14-107, isolated from an unidentified sponge, furnished 143, 147, austalides S-U (150-152), A (153), B (154), D (155), E (156), G (157), I (158), J (159), L (160) (Figure 15). Compounds 152 and 154 displayed an antiviral activity against the influenza A virus (H1N1), with $\mathrm{IC}_{50}$ values of 90 and $99 \mu \mathrm{M}$, respectively [18]. Austalides V-X (161-163) (Figure 15) were isolated, together with 138, 139, 143, 148, 149 and 160, from the marine sediment-derived fungus Penicillium rudallense. Compounds 161 and 162 displayed significant inhibitory activity on RANKL-induced osteoclast differentiation with $\mathrm{ED}_{50}$ values of 1.9-2.8 $\mu \mathrm{M}$ [32]. 


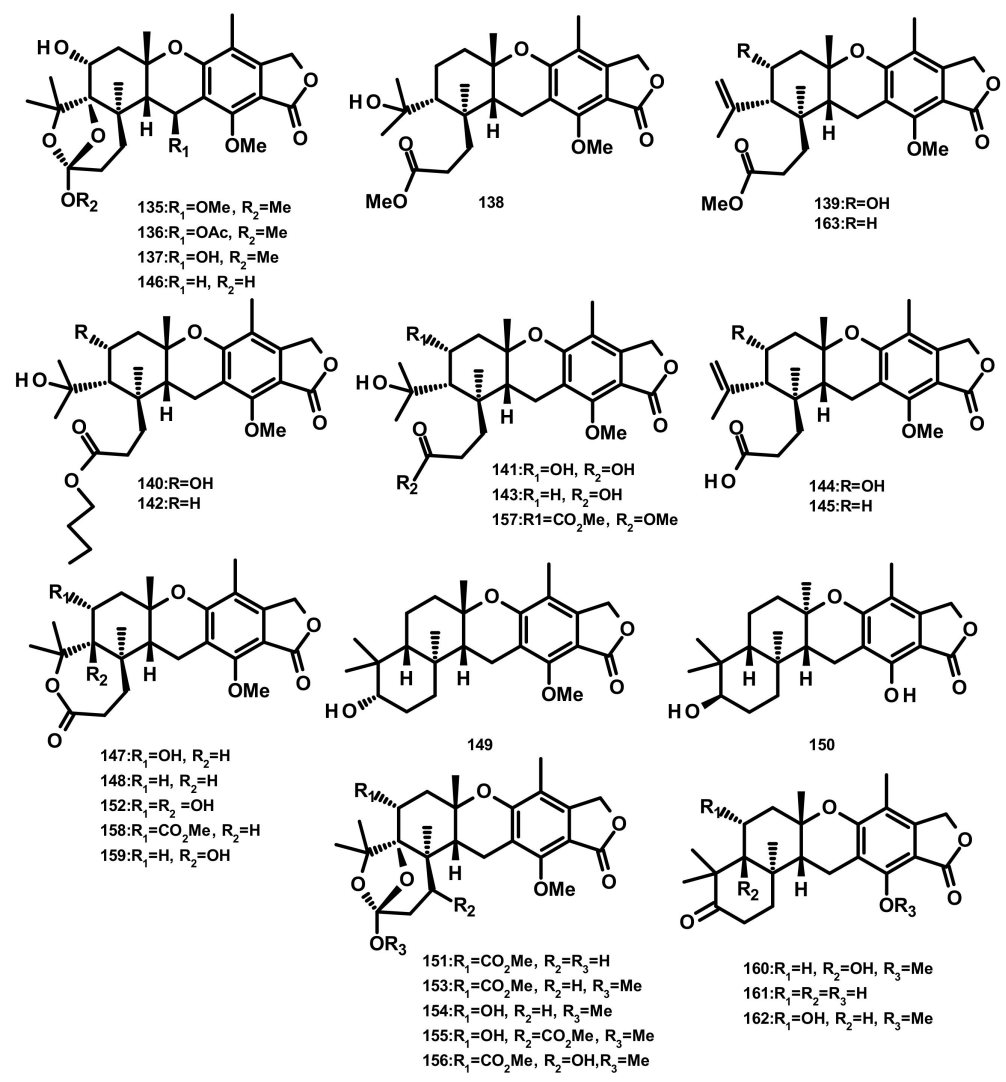

Figure 15. Chemical structures of australides 135-163.

Drimane Sesquiterpenes Linked to 3,5-Methylorsellinic Acid

Austinoids and Related Compounds (Figures 16-18)

Merosesquiterpenes of the austinoid group can be arbitrarily divided, according to their structural variances, into austinoids (Figure 16), dehydroaustinoids (Figure 17) and isoaustinoids (Figure 18). For practical aspects of the discussion of these compounds, they will not be categorized into any particular group.

Austinol (165) (Figure 16), dehydroaustin (172) and 11 $\alpha$-acetoxyisoaustinone (189) (Figure 18) were isolated from the culture extract of Penicillium citrinum, which was obtained from the mangrove Bruguiera sexangula var. rhynchopetala, collected in the South China Sea. Compounds 165, 172 and 189 showed selective antibacterial activity against five terrestrial and two marine pathogenic bacteria, particularly 165 displayed moderate activity against Staphylococcus epidermidis and S. aureus with MIC values of $10 \mu \mathrm{M}$. However, these compounds showed no cytotoxicity $\left(\mathrm{IC}_{50}>50 \mu \mathrm{M}\right)$ against HeLa, MCF-7 and A549 cell lines [51]. Talaromytin (167) (Figure 16), isolated from the marine seaweed-derived fungus Talaromyces sp. CX11, exhibited no cytotoxicity against a panel of human tumour cell lines, including HL-60, K562, MGC-803, BEL-7402, SH-SY5Y, HCT-116, MDA-MB-231, A549, MCF-7/ADM, HO8910, U87 and NCI-H1975 [19]. Further structurally related austinoids, namely austin (164), 172, dehydroaustinol (173), 7-hydroxydehydroaustin (174), acetoxydehydroaustin (175) (Figure 17) and 189, were isolated from the marine-derived fungus Pestalotiopsis sp. PSU-ES194, which was obtained from leaves of the seagrass Enhalus acoroides. Compound $\mathbf{1 7 5}$ displayed weak cytotoxicity against Vero cells with an $\mathrm{IC}_{50}$ value of $48 \mu \mathrm{M}$ [52]. Long et al. [21] described the isolation of 164, 165, 172, 173, 175, 1, 2-dihydroacetoxydehydroaustin (180), 2-hydroacetoxydehydroaustin (184) (Figure 17), isoaustinone (186) (Figure 18), and 189, from the culture of the fungus Aspergillus sp. 16-5c, which was obtained from leaves of the mangrove plant Sonnera tiaapetala, collected on the coastal salt marsh of the South China Sea. Compounds 172, 173 and 186 exhibited inhibitory activity against AChE with $\mathrm{IC}_{50}$ values 
of $0.40,3.00$ and $2.50 \mu \mathrm{M}$, respectively. Later on, Liu et al. described the isolation of a new austinoid derivative, 1,2-dehydroterredehydroaustin (183) (Figure 17), together with the previously reported 175 and 180, from Aspergillus terreus H010, which was isolated from the mangrove tree Kandelia obovata. The absolute configurations of the stereogenic carbons of $\mathbf{1 8 0}$ were determined by comparison of the calculated and experimental ECD spectra. Compound 180 exhibited weak anti-inflammatory activity with an $\mathrm{IC}_{50}$ value of $42.3 \mu \mathrm{M}$ [53] (Figures 16 and 17).
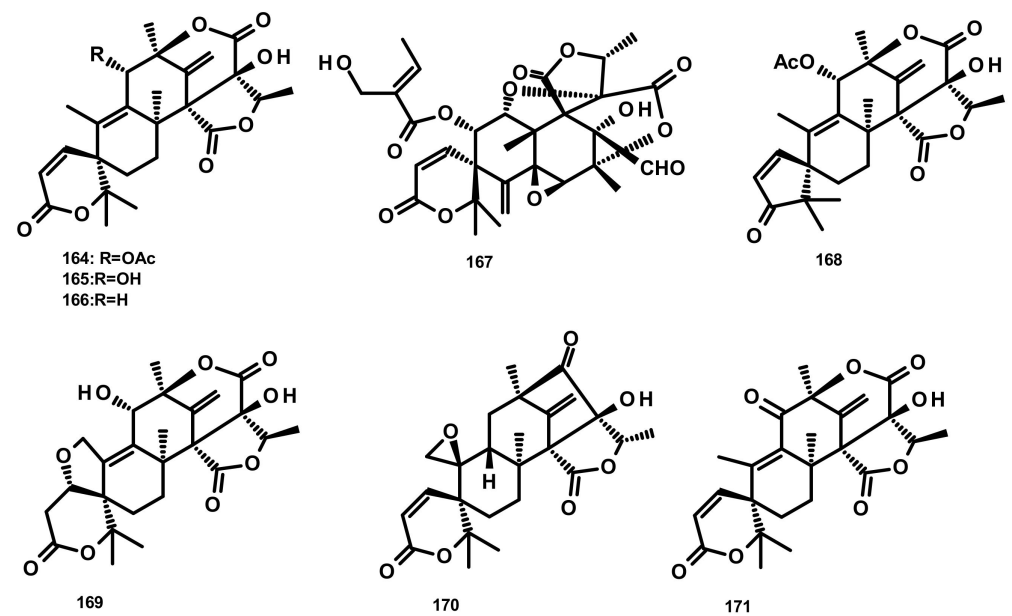

Figure 16. Chemical structures of austinoids 164-171.

Two previously unreported austinoid derivatives, furanoaustinol (169) (Figure 16) and 7-acetoxydehydroaustinol (176) (Figure 17) were isolated, along with 164, 165, austinolide (166) (Figure 16), (172), 7-hydroxydehydroaustin (174) (Figure 17), 175, 11 $\alpha$-hydroxyisoaustinone (188) (Figure 18) and 189, from the culture of the marine-derived fungal strain Penicillium sp. SF-549, collected from a sample of sea sand. Compound 169 showed weak inhibitory activity against protein tyrosine phosphatase $1 \mathrm{~B}$ with an $\mathrm{IC}_{50}$ value of $77.2 \mu \mathrm{M}$, whereas $166,175,176,188$, and 189 showed weak inhibition of $\mathrm{NO}$ production with $\mathrm{IC}_{50}$ values of $30.1,58.3,61.0,37.6$, and $40.2 \mu \mathrm{M}$, respectively [54]. The culture extract of Penicillium sp. TGM112, isolated from the medicinal mangrove Bruguiera sexangula var. rhynchopetala, collected in the South China Sea, afforded two previously unreported austin analogs, penicianstinoids A (185) and B (178), in addition to the previously described 164, 165, 169, 173, 174, 1, 2-dihydro-7-hydroxydehydroaustin (181) and 189. The absolute configurations of the stereogenic carbons of 178 and 185 were determined by comparison of the experimental and calculated ECD spectra using Time-Dependent Density-Functional Theory (TDDFT), while those of 169 and 181 were confirmed by X-ray analysis. Compounds 164, 165, 178 and 185 displayed growth inhibitory activity of newly hatched larvae of cotton bollworm (Helicoverpa armigera Hubner) with $\mathrm{IC}_{50}$ values of $200 \mu \mathrm{g} / \mathrm{mL}$ (the positive control azadirachtin; $\mathrm{IC}_{50}=25 \mu \mathrm{g} / \mathrm{mL}$ ). Compounds 165, 169, 173, 174, 178, 181 and 185 exhibited insecticidal activity against a nematode Caenorhabditis elegans with $\mathrm{EC}_{50}$ values ranging from $9.4( \pm 1.0)$ to $38.2( \pm 0.6) \mu \mathrm{g} / \mathrm{mL}$ [55]. Hwang et al. [56] reported the isolation of the previously reported austinoids, including 164, 172, 173, 175, 186, 5' $S$-isoaustinone (187) (Figure 18), 189, neoaustin (191) and austinoneol A (193) (Figure 18), from the culture extract of the marine-derived fungus Penicillium sp. FCH061, isolated from the underwater sediment collected off the coast of Chuja-do in Korea. It is worth mentioning that the stereostructures of these compounds in the reference are opposite to those described in this review. Asperaustins A (168) (Figure 16) and B (190) (Figure 18) were obtained, together with the previously described austinoids, i.e., 164, 172, precalidodehydroaustin (177), 186, 187, 193, from the culture extract of Aspergillus sp. ZYH026, isolated from superficial mycobiota of the brown alga Saccharina cichorioides f. sachalinensis, which was collected from the South China Sea [57] (Figure 17). The absolute structures of 168, 177, 190 and 193 were established unambiguously by 
single-crystal X-ray analysis using CuKa radiation. All the isolated compounds, except 168, were assayed for AChE inhibitory activity but none exhibited significant activity [57].
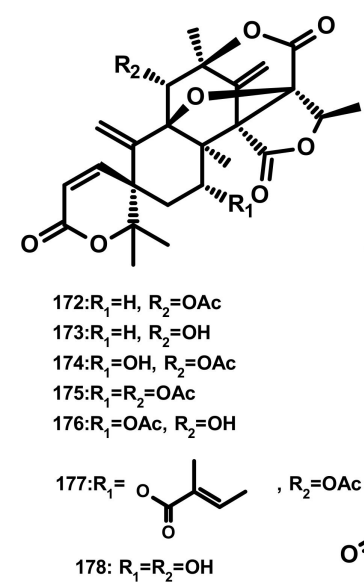

178: $\mathrm{R}_{1}=\mathrm{R}_{2}=\mathrm{OH}$

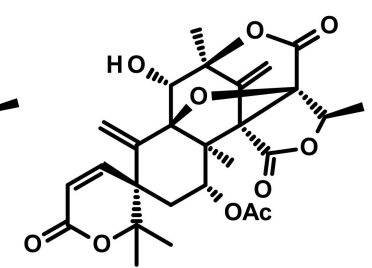

179

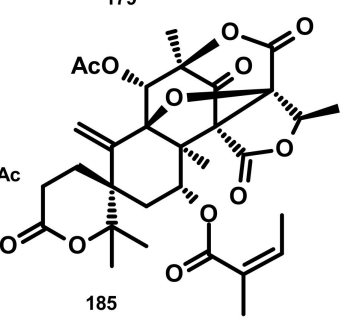

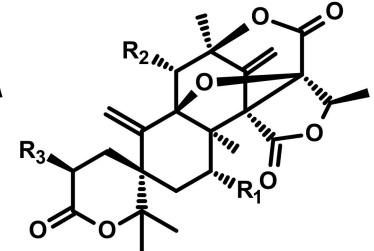

$180: R_{1}=R_{2}=O A C, R_{3}=H$

$181: \mathrm{R}_{1}=\mathrm{OH}, \mathrm{R}_{2}=\mathrm{OAC}, \mathrm{R}_{3}=\mathrm{H}$

$182: R_{1}=0 \quad, R_{2}=O A c, R_{3}=H$

$183: R_{1}=0 \mathrm{O}_{\mathrm{O}}=\mathrm{OAC}, \mathrm{R}_{3}=\mathrm{H}$

$184: R_{1}=R_{2}=O A c, R_{3}=O H$

Figure 17. Chemical structures dehydroaustinoid derivatives 172-185.

The previously unreported austinoid derivatives, brasilianoids G (194) (Figure 18), H (170), I (171) $\mathrm{J}(\mathbf{1 7 9})$ and $\mathrm{L}$ (192) were reported, together with the previously described austinoids including 165, 166, $169,172,173,174,188$ and 191, from the marine-derived fungus Penicillium brasilianum WZXY-M122-9, isolated from a marine sponges collected from the South China Sea. None of the isolated compounds exhibited either cytotoxicity against A549, RAW264.7 (mouse monocyte/macrophage) and IEC-6 (rat small intestine epithelial) cell lines or antibacterial activity against Gram-positive bacteria S. aureus ATCC 29,213 and a clinically isolate Gram-negative bacteria Klebsiella pneumoniae 58AP) [58] (Figure 18).

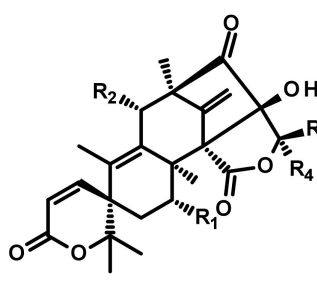

$186: R_{1}=R_{2}=R_{4}=H, R_{3}=M e$ $187: R_{1}=R_{2}=R_{3}=H, R_{4}=M e$ $188: R_{1}=H, R_{2}=O H, R_{1}=M e, R_{4}=H$ $189: R_{1}=H, R_{2}=O A c, R_{3}=M e, R_{4}=H$ $190: R_{1}=H, R_{2}=O A c, R_{3}=H, R_{4}=M e$
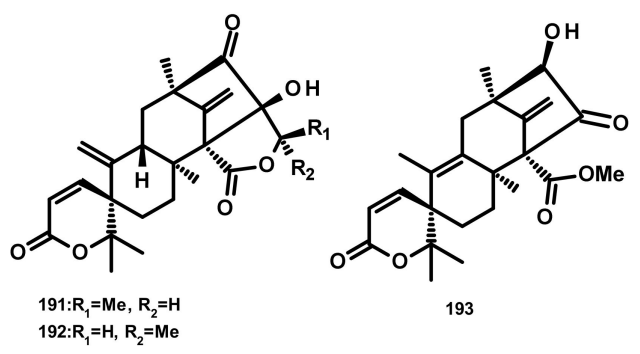

193

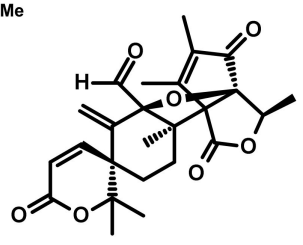

194

Figure 18. Chemical structures isoaustinoids 186-194.

Preaustinoids and Related Compounds (Figures 19 and 20)

Zhang et al. [59] reported the isolation of three new preaustinoids named 4,25-dehydrominiolutelide B (195), 4,25-dehydro-22-deoxyminiolutelide B (196) and isominiolutelide A (197), together with the previously reported berkeleyacetal A (198), berkeleyacetal B (199) and 22-epoxyberkeleydione (200) (Figure 19) from a static culture of the fungus Penicillium sp. MA-37, isolated from the rhizospheric soil of the mangrove plant Bruguiera gymnorrhiza, collected from the Hainan island. The absolute configurations of the stereogenic carbons of 195 and 197 were established 
by comparison of the experimental and calculated ECD spectra using TDDFT, whereas those of 196 were determined by single-crystal X-ray analysis using CuKa radiation. Li et al. [60] described the isolation of two new analogues of berkeleyacetal (which were later reisolated by Hoang et al. [61] and named 22-deoxyminiolutelide B (201) (Figure 20) and miniolutelide C (202) (Figure 19)), along with the previously reported 198, 200 and berkeleydione (203) (Figure 19), from Penicillium strain 303\#, obtained from sea water from Zhanjiang Mangrove National Reserve in Guangdong Province, China. Compounds 201 and 202 displayed moderate cytotoxicity against MDA-MB-435, HepG2, HCT-116, and A549 cell lines [60]. Two previously unreported preaustinoid analogs, preaustinoids E (204) and F (205), were isolated together with the previously reported preaustinoid A2 (206) (Figure 19) and preaustinoid D (207) (Figure 20) from the underwater sediment-derived fungus Penicillium sp. FCH061. The relative stereochemistry of $\mathbf{2 0 4}$ and $\mathbf{2 0 5}$ was determined by nuclear overhauser effect spectroscopy (NOESY) correlations and compared with that of the previously reported compounds [56]. Zhang et al. [62] described the isolation of six new preaustinoid derivatives namely brasilianoids A (208), B (204), C (205), D (209), E (210) and F (211) (Figure 19), together with the previously reported 206 and 207, from a marine-derived fungus P. brasilianum WZXY-m122-9, isolated from an unidentified sponge. Surprisingly, the structures of brasilianoids B (204) and C (205) are found to be the same as those of preaustinoids E (204) and F (205), previously isolated by Wang et al. [56], although the stereostructures of $\mathbf{2 0 4}$ and $\mathbf{2 0 5}$ in the original article [56] are opposite to those of brasilianoid B (204) and C (205). Compound 208 significantly stimulated filaggrin and caspase-14 expressions in $\mathrm{HaCaT}$ (human keratinocyte) cells in a dose-dependent manner. Since filaggrin is a key natural moisturizing factor that maintains the ability to regulate the skin moisture barrier, 208 could be a potential cosmeceutical for skin moisturizer in the cosmetic industry. Moreover, 204 and 205 exhibited an inhibition of NO production in lipopolysaccharide (LPS)-induced RAW 264.7 macrophages whereas 204-206 $(10 \mu \mathrm{M})$ inhibited the expression of the hepatitis B virus (HBV) DNA in HepG2.2.15 cells with the inhibitory rates of 25,15 , and $10 \%$, respectively. Later on, the same group has reported a new preaustinoid, named brasilianoid K (212) (Figure 19) from the same fungus [58]. Chen et al. [20] reported the isolation of four new analogues of berkeleyacetals, amestolkolides A-D (213-216) (Figures 19 and 20), along with the known analogue and purpurogenolide E (217) (Figure 20), from the culture extract of the endophytic fungus Talaromyces amestolkiae YX1, isolated from healthy leaves of the mangrove tree Kandelia obovata, collected from Zhanjiang Mangrove Nature Reserve in Guangdong, China. The absolute configurations of the stereogenic carbons of 213 and 216 were established by comparison of their calculated and experimental ECD spectra, whereas the stereostructures of $\mathbf{2 1 4}$ and 215 were established by a single-crystal X-ray diffraction analysis using $\mathrm{CuK} \alpha$ radiation. Compounds 213 and 214 were tested for their anti-inflammatory activity by inhibition of the LPS-activated NO production in RAW264.7 cells for which 213 showed strong inhibitory activity with an $\mathrm{IC}_{50}$ value of $(1.6 \pm 0.1 \mu \mathrm{M})$ whereas 214 exhibited only weak activity, with an $\mathrm{IC}_{50}$ value of $30 \pm 1.2 \mu \mathrm{M}$ [20]. The organic extract of the culture extract of the marine sponge-associated fungus Eupenicillium sp. 6A-9, isolated from the inner tissue of the marine sponge Plakortis simplex, which was collected from Yongxing Island, China, furnished five new preaustinoids, namely eupeniacetals A (218) and B (219), preaustinoid A3 (230) (Figure 20), 1-methoxyhydropreaustinoid A1 (same as preaustinoid D) (207), hydroberkeleyone B (221) and 22-deoxy-10-oxominiolutelide B (222) (Figure 20), together with five previously reported preaustinoid derivatives including 198, 201, preaustinoid A1 (223) and berkeleyone C (224) (Figure 20). All the isolated compounds, except 224, exhibited inhibitory effects on tumour necrosis factor- $\alpha$ (TNF- $\alpha$ ) secretion in LPS-induced THP-1 (leukemic monocyte) cells, with IC $_{50}$ values ranging from 22.6 to $72.2 \mu \mathrm{M}$ (pomalidomide, $\mathrm{IC}_{50}=0.23 \mu \mathrm{M}$ ) [63]. Using the OSMAC (One Strain Many Compounds) approach and a metabolomic-oriented strategy, Hoang et al. [61] were able to identify and isolate two previously undescribed preaustinoids 22-deoxyminiolutelide A (225) and 4S-hydroxy-22-deoxyminiolutelide B (226), together with other previously reported preaustinoids including 198, 201, 202, 218, 222, miniolutelide A (227) and miniolutelide B (228) (Figure 20), from the culture extract of the marine-derived fungus Penicillium ubiquetum MMS330, isolated from a sample of 
the blue mussel Mytilus edulis, collected at Port Giraud on the Loire estuary in France. All the isolated compounds, except 222, were evaluated for their cytotoxicity against KB (keratin-forming tumour) and MCF-7 cell lines, however, neither of them exhibited significant activity. The previously undescribed preaustinoid derivatives, preaustinoids A6 (229) and A7 (220) (Figure 20) were reported, together with the previously described 206, 224, and preaustinoid A3 (230) (Figure 20), from the marine-derived fungus Penicillium sp. SF-5497. Compound 224 and 229 inhibited PTP1B (a member of the protein tyrosine phosphatase (superfamily) activity in a dose-dependent manner with $\mathrm{IC}_{50}$ values of 58.4 and $17.6 \mu \mathrm{M}$, respectively. Mechanistic study revealed that 201 inhibited PTP1B in a noncompetitive manner and preferentially bound to the free enzyme rather than to the enzyme-substrate complex [64]. Wen et al. [57] reported the isolation of a preaustinoid, named asperaustin $C$, from the algicolous fungus Aspergillus sp. ZYH026, which was claimed to be a new compound. The structure of asperaustin C, whose structure and absolute configurations of its stereogenic carbons were confirmed by X-ray analysis using $\mathrm{Cu} \mathrm{K} \alpha$ radiation, was found to be the same as that of the previously described brasilianoid $\mathrm{B}$ (204). As the absolute configurations of the stereogenic carbons of preaustinoids $E$ (204) and F (205), preaustnoid A2 (206) and preaustinoid D (207), reported by Hwang et al. [56], were determined by comparison with those described before the revision of the absolute configurations by Zhang et al. [62] and Wen et al. [57], the stereostructures of these compounds are opposite to those presented in this review.

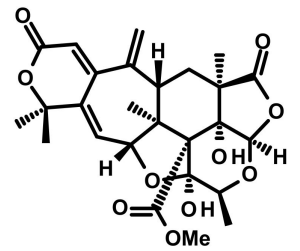

195

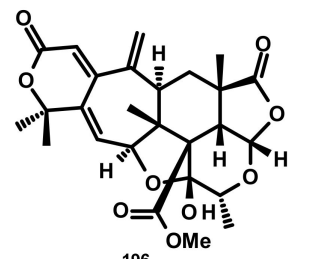

196
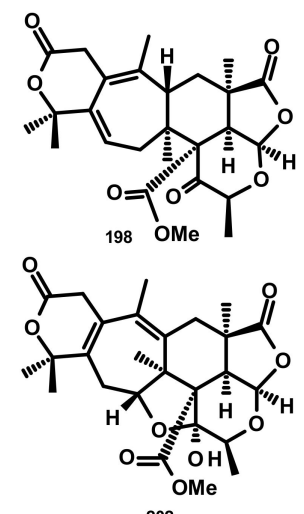

202
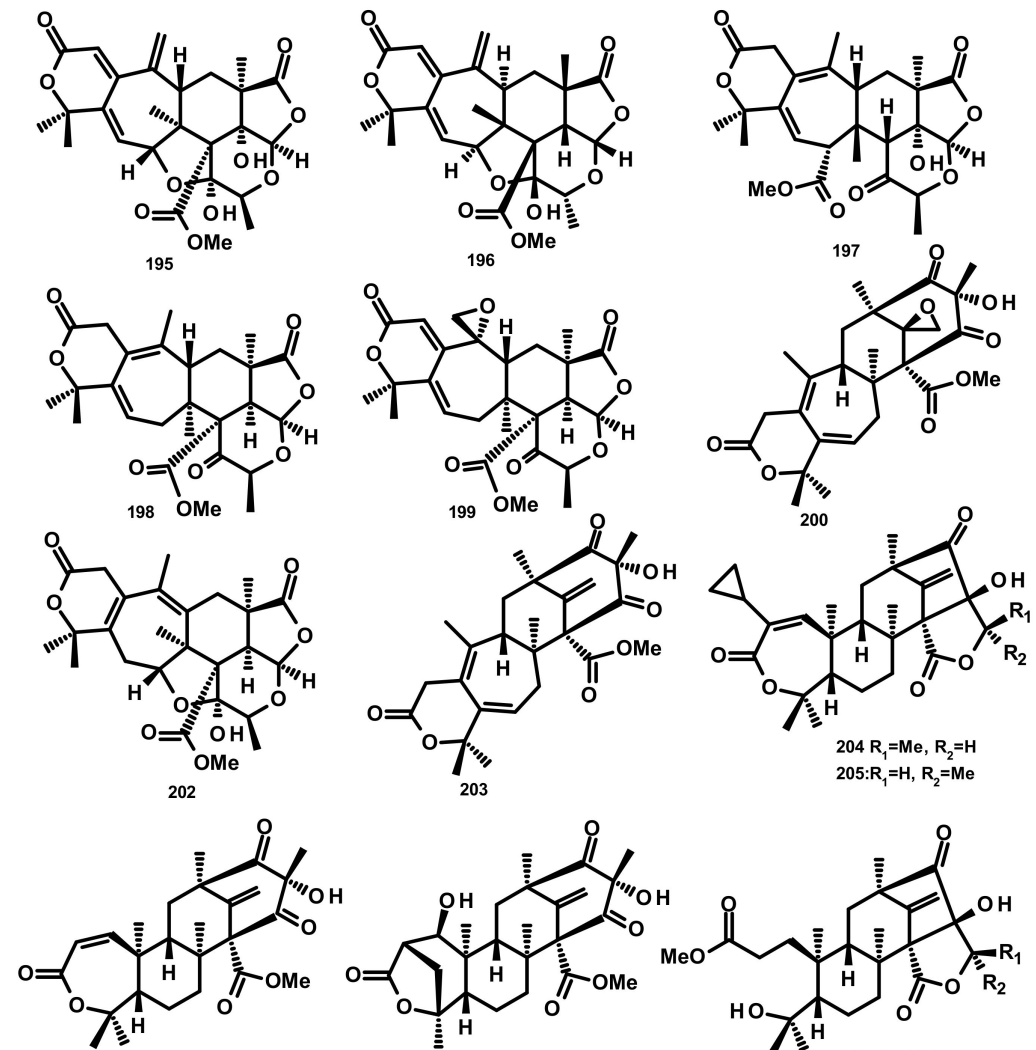

206
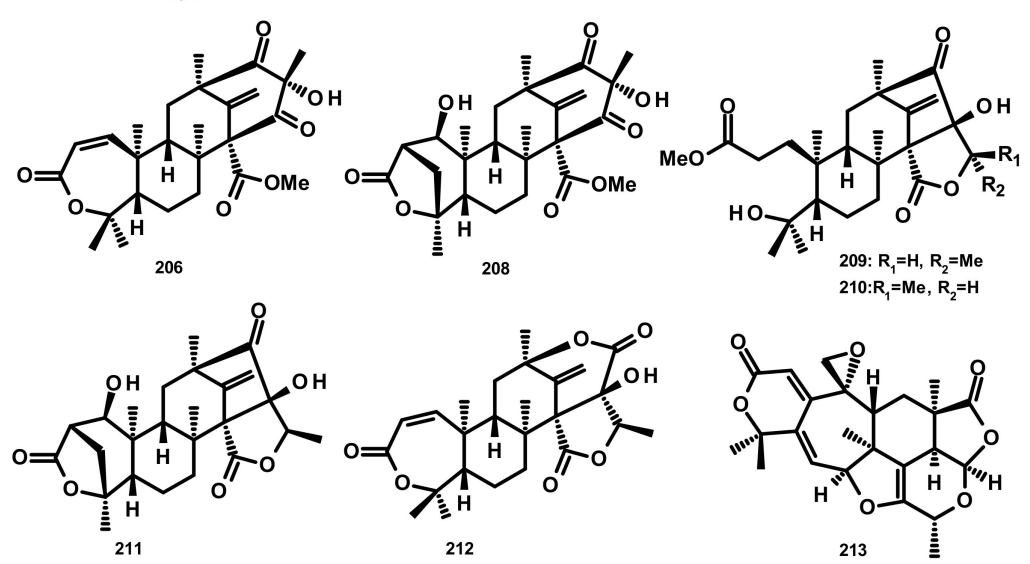

208
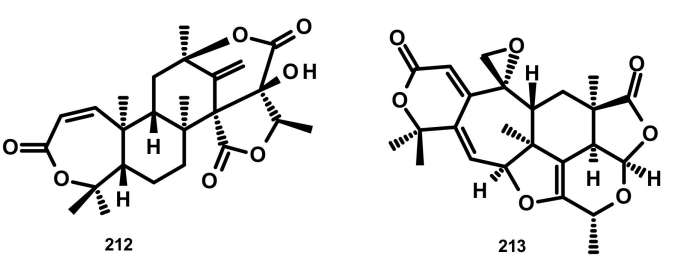

Figure 19. Chemical structures of preaustinoids 195-200, 202-206 and 208-213. 


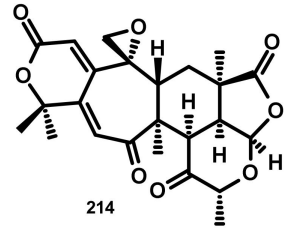

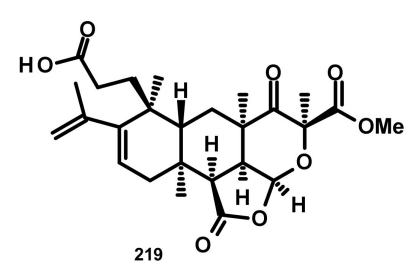

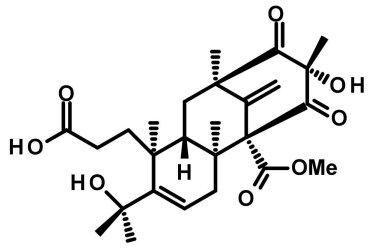

221

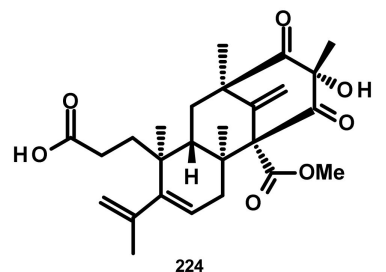

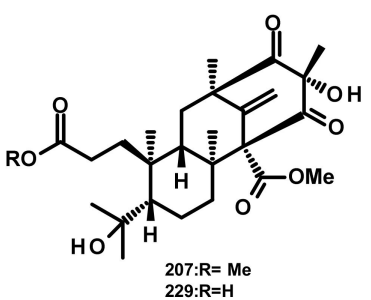

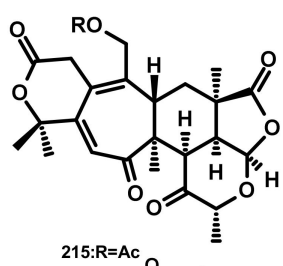<smiles>CC(=O)CC(C)C</smiles>

217:R=H

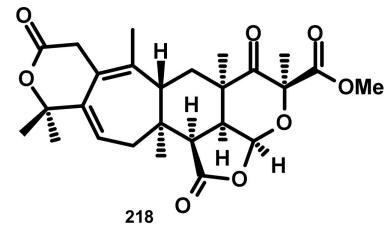

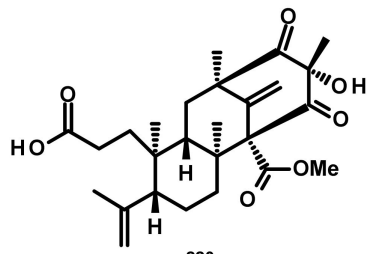

220

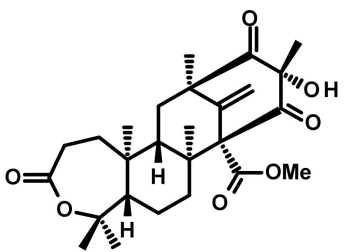

223

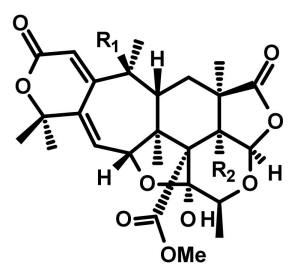

201: $R_{1}=R_{2}=H$ 226: $\mathrm{R}_{1}=\mathrm{OH}, \mathrm{R}_{2}=\mathrm{H}$ 228: $\mathrm{R}_{1}=\mathrm{H}, \mathrm{R}_{2}=\mathrm{OH}$

Figure 20. Chemical structures of preaustinoid derivatives 201, 207 and 214-230.

Terretonins and Related Compounds (Figure 21)

Terretonins E (231) and F (232) (Figure 21) were isolated from the culture extract of the marine derived-fungus Aspergillus insuetus, isolated from the marine sponge Petrosia ficiformis which was collected in the Mediterranean Sea. Compounds 231 and 232 inhibited NADH oxidase activity (in beef heart submitochondrial particles) with $\mathrm{IC}_{50}$ values of $3.90 \pm 0.4$ and $2.97 \pm 1.2 \mu \mathrm{M}$, respectively [65]. The culture extract of the marine sponge-associated fungus Aspergillus sp. OPMF00272 furnished terretonin G (233) and terretonin (234) (Figure 21). Compound 233 (20 mg per $6 \mathrm{~mm}$ disk) exhibited antibacterial activity against Gram-positive bacteria (S. aureus FDA209P, B. subtillis PCI219 and M. luteus ATCC9341), but not against Gram-negative bacteria (P. aeruginosa IFO12689 and E. coli JM109) and yeast (C. albicans ATCC64548 and S. cerevisiae S288c) [66]. Chemical examination of the endophytic fungus Aspergillus terreus EN-539, obtained from the fresh tissue of the marine red alga Laurencia okamurai which was collected from the coast of Qingdao, China, led to the isolation of the previously unreported terretonin analogue, aperterpene $\mathrm{O}$ (235), together with the previously described terretonins $\mathrm{A}$ (236) (Figure 21) and G (233) [67]. Compound 233 exhibited antimicrobial activity against M. luteus and S. aureus with MIC values of 32 and $8 \mu \mathrm{g} / \mathrm{mL}$, respectively [67]. A new terretonin analog terretonin $\mathrm{O}$ (237) was isolated, together with the previously reported terretonins $M$ (238) and N (239) (Figure 21) from the culture extract of Aspergillus terreus LGO13, obtained from a sediment sample collected from sewage water containing heavy metals. Compound 237 displayed weak antimicrobial activity 
against P. aeruginosa and S. aureus [68]. The previously unreported terretonin D1 (240) (Figure 21) was isolated, together with the previously described 234, 236 and terretonin D (241) (Figure 21), from the marine-derived fungus Aspergillus terreus ML-44, obtained from the fresh gut of pacific oyster. All the isolated compounds displayed a weak inhibition of NO production in the LPS-stimulated RAW264.7 macrophages [69]. It is interesting to note that only the relative configurations of the structures of 231-233 were determined. On the contrary, the absolute configurations of the stereogenic carbons of 237-241 were established, with absolute confidence, by X-ray analysis using $\mathrm{CuK} \alpha$ radiation with good Flack parameter. Therefore, it is possible that the structures of 231-233 are the enantiomeric form of their correct structures.

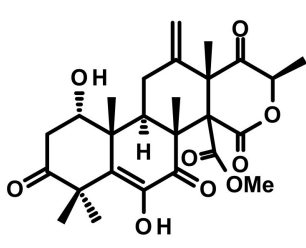

231

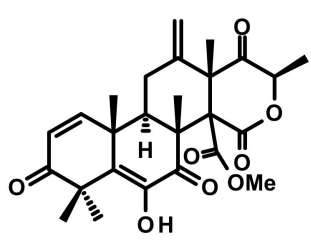

232

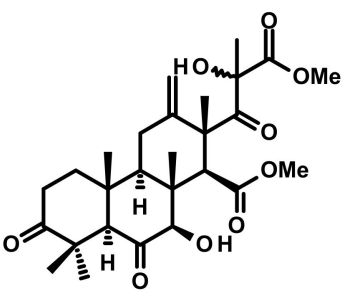

233

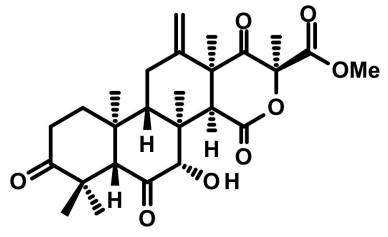

240

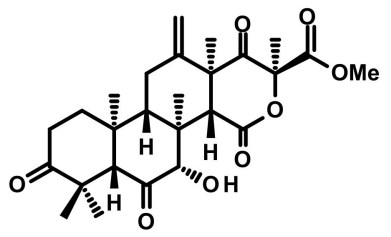

241

Figure 21. Chemical structures of terretonin derivatives 231-241.

Andrastins and Related Compounds (Figure 22)

The andrastin derivatives, 15-deacetylated citreohybridone E (242), 3-deacetylated andrastin A (243), andrastin A (244), 3-deacetylcitreohybridonol (245), citreohybridonol (246), andrastin B (247), 6- $\alpha$-hydroxyandrastin B (248) and dihydrocitreohybridonol (249) (Figure 22), were isolated from the marine-derived fungus Penicillium sp. YPGA11, obtained from the deep-sea water at a depth of $4500 \mathrm{~m}$ in the Yap Trench, West Pacific Ocean. Compounds 242-249 exhibited inhibitory activity against NO production in LPS-activated RAW 264.7 macrophages with inhibition rates ranging from $60 \%$ to $90 \%$ at $50 \mu \mathrm{M}$, but decreased sharply at $25 \mu \mathrm{M}$. Since these compounds were also cytotoxic to the RAW 264.7 cells (45-65\% inhibition at $50 \mu \mathrm{M})$, it is believed that their inhibition of NO production was attributed to cell death [70]. Chemical examination of the algicolous fungus Aspergillus terreus EN-539 led to the isolation of another andrastin derivative named aperterpene N (250) (Figure 22) [67]. Compound 250 displayed the in vitro inhibitory activity against the influenza neuraminidase with an $\mathrm{IC}_{50}$ value of $18.0 \mathrm{nM}$ [67]. Andrastone A (251), 16-epi-citreohybriddione (252) and citreohybriddione A (253) (Figure 22) were recently isolated from the marine-derived fungus P. allii-sativi, isolated from the deep-sea water of the western Pacific. All the isolated compounds were evaluated for their antiproliferative effects against HepG2, A549, BIU-87 (urinary bladder), BEL-7402, ECA-109 (esophageal squamous carcinoma), HelaS3 (cervix), and PANC-1 (prancreatic) human tumour cell lines; however, only 251 displayed significant activity, with selective effect against HepG2 tumour cells 
with an $\mathrm{IC}_{50}=7.8 \mu \mathrm{M}$. Compound 251 also significantly increased caspase- 3 and caspase- 8 activities, but exhibited almost no effect on caspase-9. Moreover, this compound was found to increase the reporter transcriptional activation of $R X R \alpha$ (retinoid $X$ receptor $\alpha$ ) while reducing the transactivity of $R X R \alpha$ induced by 9-cis-retinoic acid in the luciferase reporter gene assay [71]. It is interesting to note that the absolute configurations of the stereogenic carbons of the sesquiterpene skeleton of 250, i.e., C-5, C-8, C-9, C-10, C-13 and C-14 are opposite to those of 242-249 and 252-253. Biogenetically, this is improbable. Even though the absolute structures of 249 [70] and 253 [71] were established by X-ray analysis, and those of 242-244 [70], 251 and 252 [71] were determined by comparison of the experimental and calculated (using TDDFT) ECD spectra, the parameters of the methods of determination of the configurations such as the flack parameter (in X-ray crystallography) and the precise wave length in the ECD curves of the experimental and calculated spectra should be duly taken into consideration.

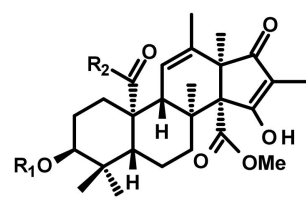

$242: R_{1}=A c, R_{2}=O H$ $243: R_{1}=A C, R_{2}=H, R_{2}=H$
24t $244: R_{1}=A c, R_{2}=H$

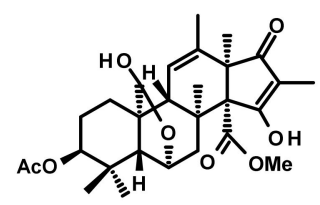

249
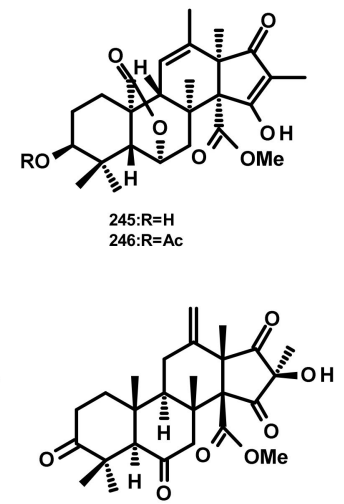

250

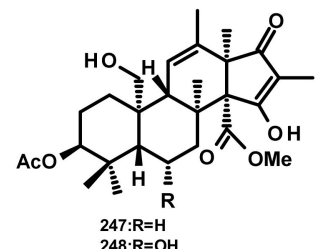

$248: \mathrm{R}=\mathrm{OH}$

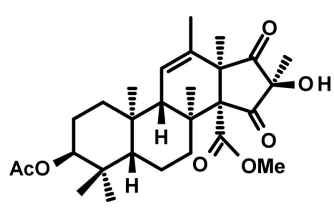

25

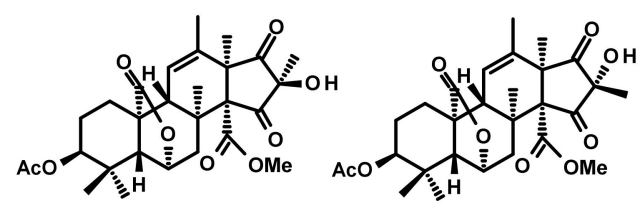

252

253

Figure 22. Chemical structures of andrastin derivatives 242-253.

Drimane Sesquiterpenes Linked to Rearranged 3,5-dimethylorsellinic Acid (Figure 23)

Simpterpenoid A (254) (Figure 23), a merosesquiterpene containing a highly functionalized cyclohexadiene with gem-propane-1,2-dione and methylformate groups, was isolated from the culture extract of Penicillium simplicissimum MA-332, obtained from the rhizospheric soil of the marine mangrove plant Bruguiera sexangula var. rhynchopetala. Compound 254 exhibited potent in vitro inhibitory activity against the influenza neuraminidase with an $\mathrm{IC}_{50}$ value of $8.1 \mathrm{nM}$ (positive control: Oseltamivir; $\mathrm{IC}_{50}=3.2 \mathrm{nM}$ ) but weak growth inhibitory activity against a plant pathogenic fungus Physalospora piricola [72].

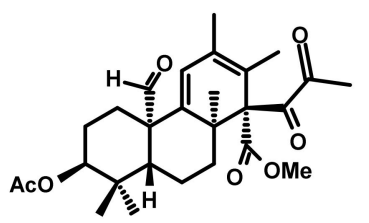

254

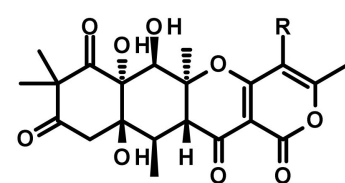

$255: R=M e$
$257: R=H$

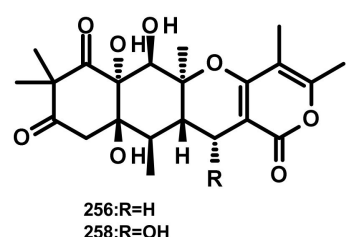

258: $\mathrm{R}=\mathrm{OH}$

Figure 23. Chemical structures of 254-258. 
Rearranged Drimane Sesquiterpenes Linked to an Isochromone (Figure 23)

The highly oxygenated merosesquiterpenes containing a rearranged drimane linked to an isochromone moiety, aspertetranones A-D (255-258) (Figure 23), were isolated from the culture extract of the endophytic fungus Aspergillus sp. ZL0-1b14 obtained from the marine green algal species of the genus Enteromorpha, which was collected from Jinjiang Dongshi salt pan in Fujian Province, China. Compounds 255-258 displayed weak inhibitory activities against TNF- $\alpha$ and NO production by LPS-stimulated RAW264.7 macrophages [73].

\subsection{Meroditerpenoids}

Naturally occurring meroditerpenoids can be categorized into three main classes: (i)-diterpenes combined with 3,5-dimethylorsellinic acid, (ii)-diterpenes combined with polyketides, and (iii)diterpenes combined with indole derivatives.

\subsubsection{Diterpenes Linked to 3,5-Dimethylorsellinic Acid (Figure 24)}

Terreusterpenes A-C (259-261) (Figure 24) were isolated from the culture extract of Aspergillus terreus, obtained from the inner part of the soft coral Sarcophyton subviride which was collected from the Xisha Island, China. Compounds $\mathbf{2 5 9}$ and $\mathbf{2 6 0}$ exhibited potent inhibitory activity against BACE1 ( $\beta$-site amyloid precursor protein-cleaving enzyme 1) with $\mathrm{IC}_{50}$ values of 5.98 and $11.42 \mu \mathrm{M}$, respectively [74]. BACE1 was identified as being responsible for the formation of amyloid beta (A $\beta$ ) which is a highly aggregatory peptide segment of the membrane-associated amyloid precursor protein. Since A $\beta$ aggregate is one of the targets for the drug discovery for Alzheimer's disease (AD), 259 and $\mathbf{2 6 0}$ could be an interesting model for a development of AD's drugs.
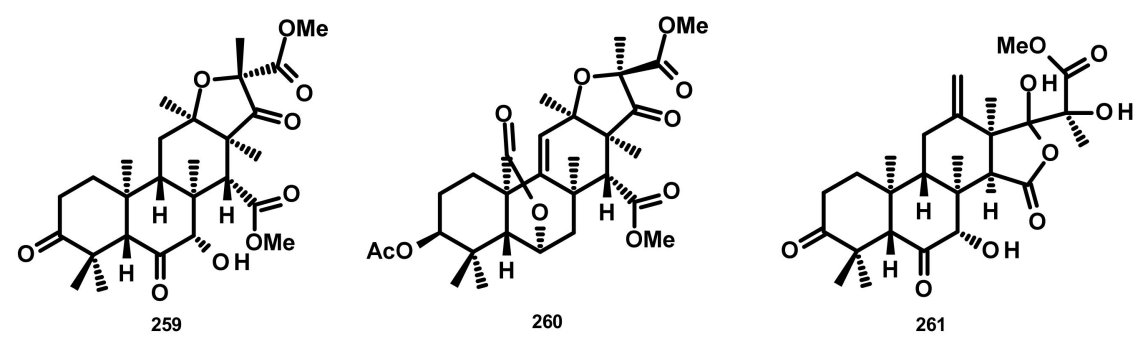

Figure 24. Chemical structures of 259-261.

\subsubsection{Diterpenes Linked to Polyketides (Figure 25)}

Aszonapyrones A (262) and B (263) (Figure 25), two tricyclic meroditerpenes containing a 2-pyrone ring, were isolated from the culture extract of the diseased coral-derived fungus Neosartorya laciniosa KUFC 7896, whereas sartorypyrone B (264) (Figure 25) was isolated from the culture extract of the marine sponge-associated fungus $N$. tsunodae KUFC 9213 which was obtained from the marine sponge Aka coralliphaga, collected from the Gulf of Thailand. Compounds $\mathbf{2 6 2}$ and $\mathbf{2 6 4}$ were examined for their cytotoxic activity against MCF-7, NCI-H460 and A375-C5 (melanoma) cell lines, using the protein binding dye sulforhodamine B (SRB) method. Compound 262 displayed potent growth inhibitory activity against the three cell lines, with $\mathrm{GI}_{50}$ values of $13.6 \pm 0.9,11.6 \pm 1.5$ and $10.2 \pm 1.2 \mu \mathrm{M}$, respectively, whereas $\mathbf{2 6 3}$ exhibited no activity at a concentration as high as $150 \mu \mathrm{M}$. Compound 264 also showed strong growth inhibitory activity against the same tumour cell lines, although less than that of 262, with $\mathrm{GI}_{50}$ values of $17.8 \pm 7.4,20.5 \pm 2.4$ and $25.0 \pm 4.4 \mu \mathrm{M}$, respectively [75]. Compound 262 also exhibited potent antibacterial activity against $S$. aureus ATCC 25,923 and B. subtilis ATCC 6633, with the MIC values of $8 \mu \mathrm{g} / \mathrm{mL}$, and multidrug-resistant S. aureus MRSA and Enterococcus spp. VRE isolates, with the MIC values of 8 and $16 \mu \mathrm{g} / \mathrm{mL}$, respectively. Although 262 showed partial synergism with the antibiotics oxacillin and ampicillin against MRSA and VRE isolates, respectively, it showed a clear synergistic effect with vancomycin (VA) against the two VRE isolates tested (E. faecalis W1 and 
E. faecium W5). Moreover, 262, at the MIC and 2 MIC concentrations, completely inhibited biofilm formation of S. aureus ATCC 25,923, B. subtilis ATCC 6633 and the multidrug-resistant S. aureus B1 and E. faecalis W1. However, S. aureus ATCC 25,923 and S. aureus B1 produced more biofilm at the subinhibitory concentration (1/2 MIC) of 262 [76]. A new aszonapyrone analogue, sartorypyrone C (268) (Figure 25), was isolated from the culture extract of the marine-derived fungus N. paulistensis KUFC 7897, obtained from the marine sponge Chondrilla australiensis, collected from the Gulf of Thailand [76]. Sartorenol (265) (Figure 25), a triclyclic meroditerpene, was isolated, together with 262 and chevalone B (266) (Figure 25), from the algicolous fungus N. takakii KUFC 7898, obtained from the marine macroalga Amphiroa sp., collected in the Gulf of Thailand. Compound 265 showed no antibacterial activity against the above-mentioned four reference strains and environmental multidrug-resistant isolates [77]. Chemical examination of the marine-derived fungus $N$. siamensis, isolated from the sea fan Rumphella sp. which was collected from the Andaman Sea of Thailand, led to the isolation of chevalone C (267) (Figure 25). Compound 267 exhibited moderate cytotoxicity against three tumour cell lines including colon HCT-116, liver HepG2 and melanoma A375 with $\mathrm{IC}_{50}$ values ranging from 24 to $153 \mu \mathrm{M}$ [78]. Compound 266 was also recently reported from Aspergillus sp. H30 which was isolated from a sea cucumber Cucumaria japonica, collected from the South China Sea. Although $\mathbf{2 6 6}$ displayed weak antimicrobial activity against $C$. albicans SC5314 and methicillin-resistant $S$. aureus (MRSA), it exhibited cytotoxic activity against BC1 (lymphoma), KB, and NCI-H187 tumour cell lines [79].

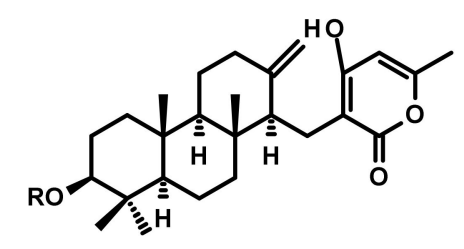

262: $R=A c$ 263:R=H

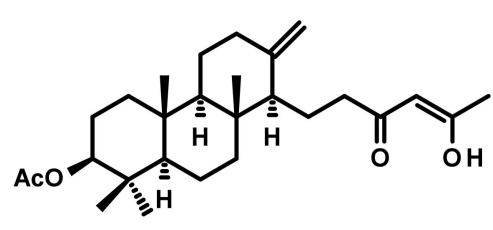

265

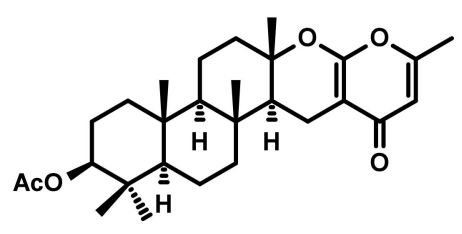

267

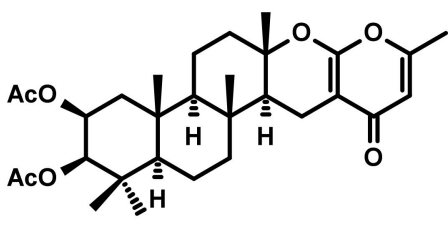

264<smiles>Cc1cc2c(c(=O)o1)C[C@H]1CC[C@H]3C(C)(C)[C@H](C)CC[C@]3(C)[C@H]1CC[C@@]2(C)O</smiles>

266

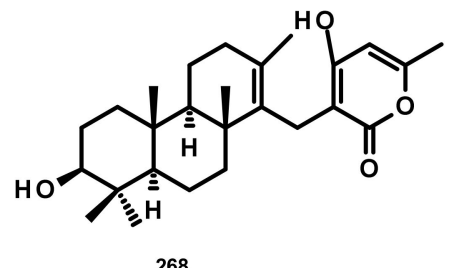

Figure 25. Chemical structures 262-268.

\subsubsection{Indole Diterpenoids (Figure 26-28)}

Rhizovarins A-F (269-274), secopenitrem D (275), PC-M4 (276), penitrems A-F (277-282), penijanthine A (283), paxilline (284), 1'-O-acetylpaxilline (285), 4b-deoxy-1'-O-acetylpaxilline (286), 3-deoxo-4b-deoxypaxilline (287) and 3b-hydroxy-4b-desoxypaxilline (288) (Figure 26) are indoloditerpenoids isolated from the culture extract of the endophytic fungus Mucor irregularis QEN-189 which was obtained from the fresh inner tissue of the stem of the mangrove plant Rhizophora stylosa, collected on Hainan Island. Compounds 269, 270, 277, 282 and 288 exhibited growth inhibitory activity against human A-549 and HL-60 cancer cell lines ( $\mathrm{IC}_{50}$ values ranging from 2.6-11.5 $\mu \mathrm{M}$ ) whereas 281 was active only against A-549 cancer cell line [80]. 

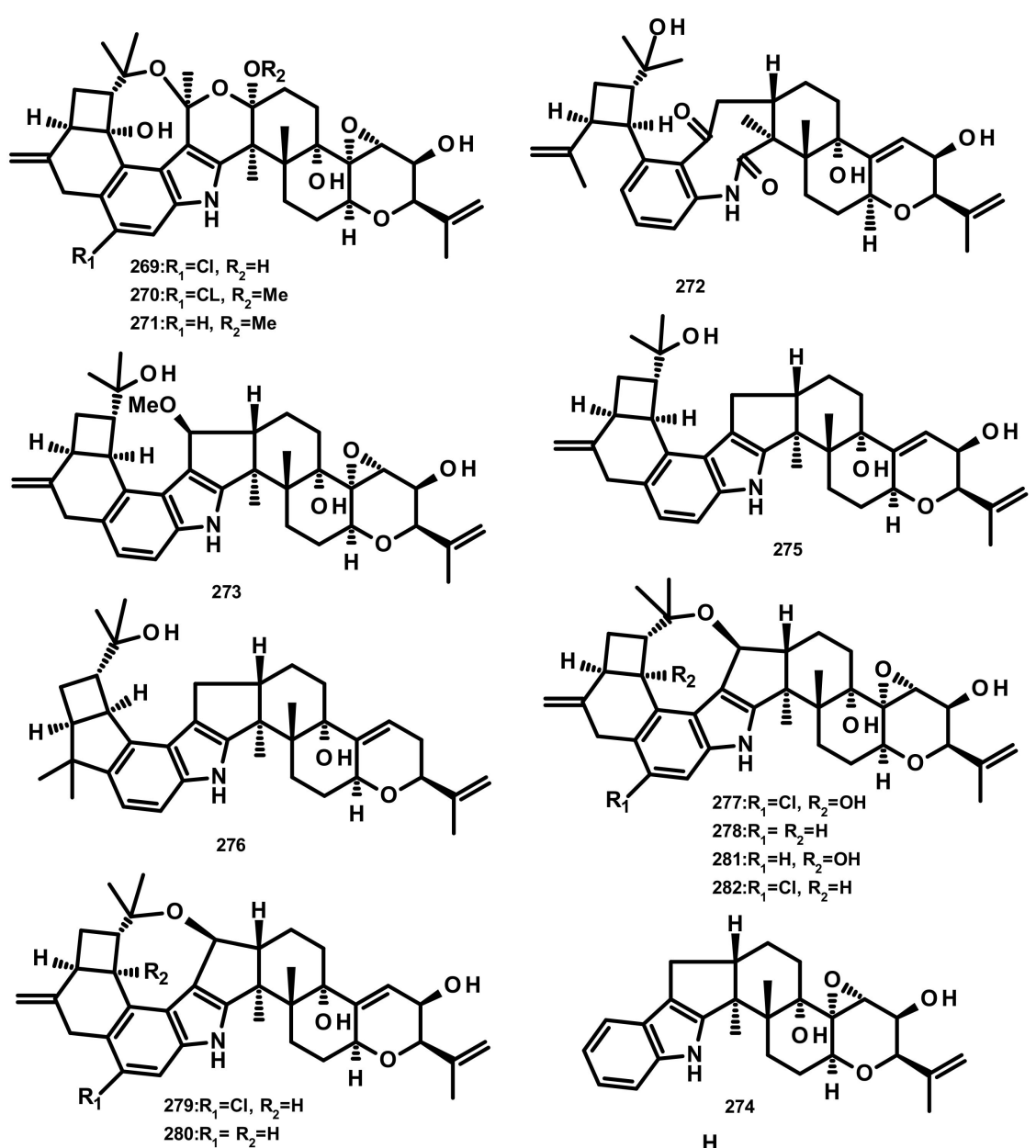

$281: \mathrm{R}_{1}=\mathrm{H}, \mathrm{R}_{2}=\mathrm{OH}$
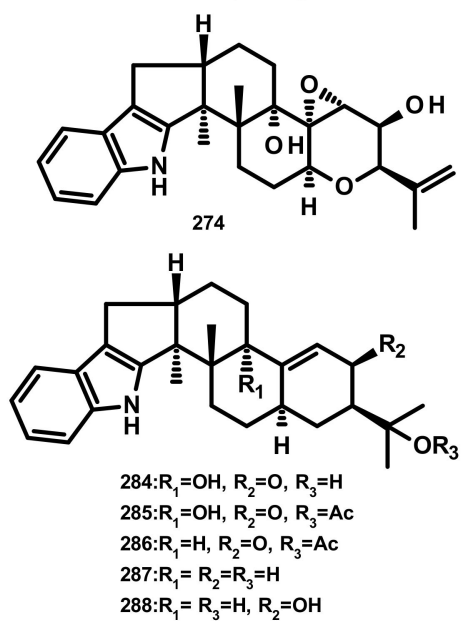

Figure 26. Chemical structures of 269-288.

Four indoloditerpenes, including $(2 R, 4 \mathrm{~b} R, 6 \mathrm{a} S, 12 \mathrm{~b} S, 12 \mathrm{c} S, 14 \mathrm{a} S)-4 \mathrm{~b}$-deoxy- $\beta$-aflatrem (289), $(2 R, 4 \mathrm{~b} S, 6 \mathrm{a} S, 12 \mathrm{~b} S, 12 \mathrm{c} R)-9$-isopentenylpaxilline $\mathrm{D}$ (290), $\beta$-aflatrem (291) and paspalinine (292) (Figure 27) were reported from the culture extract of Aspergillus flavus OUCMDZ-2205 isolated from the marine prawn (Penaeus vannamei). Compound $\mathbf{2 8 9}$ displayed weak antibacterial activity against $S$. aureus with a MIC value of $20.5 \mu \mathrm{M}$. Additionally, 289 and 290 were able to arrest the A549 cell cycle in the $S$ phase at a concentration of $10 \mu \mathrm{M}$. Moreover, 289 displayed PKC-beta inhibition with an IC 50 value of $15.6 \mu \mathrm{M}$ [81]. Two indoloditerpenes 293 and 294 (Figure 27) were isolated, together with 292, paspalicine (295) and paspaline (296) (Figure 27), from two marine-derived Aspergillus sp. AF-119 and Aspergillus sp. JQG 1-6f. Compounds 289 and 290 displayed significant antibacterial activity against a panel of bacterial isolates including S. aureus, B. subtilis and E. coli but are void of antifungal activity [82]. The culture extract of the sea anemone-derived fungus Penicillium sp. furnished 296, 22-hydroxylshearinine F (297), shearinine F (298), 6-hydroxylpaspalinine (299), paspalitrem C (300), paspalitrem A (301), 7-O-acetylemindole SB (302), emindole SB (303), 3-deoxo-4b-deoxypaxilline (304), PC-M6 (305) and 10, 23-dihydro-24, 25-dehydroaflavinine (306) (Figure 27). Compounds 297-306 were tested for their 
antibacterial activity against several human-, aqua-, and plant-pathogenic microbes; however, the tested compounds displayed antimicrobial activity in micromolar range against $P$. aeruginosa, E. coli, Vibrio parahaemolyticus and V. alginolyticus [83].

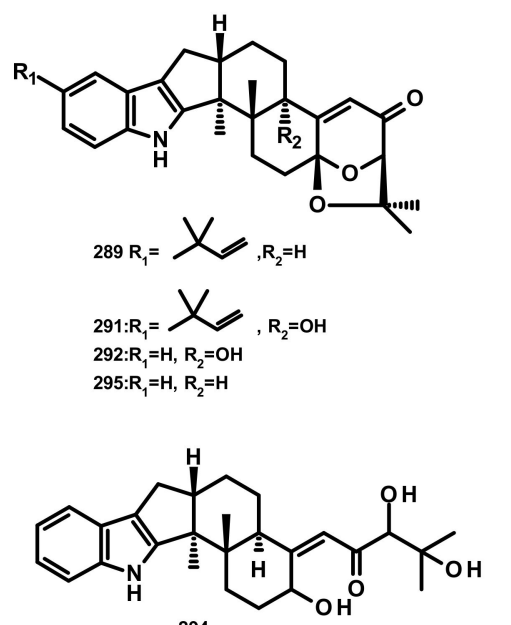

294
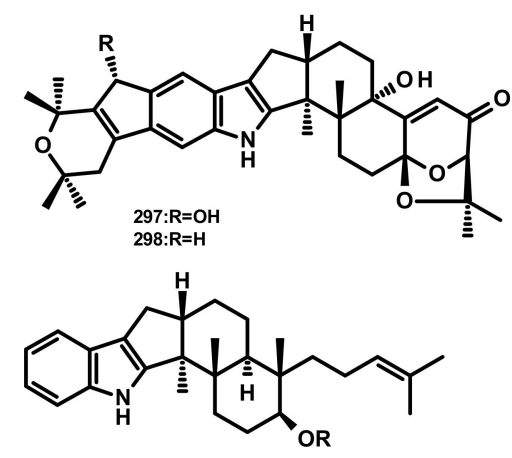

$302: R=A C$
$303: R=H$

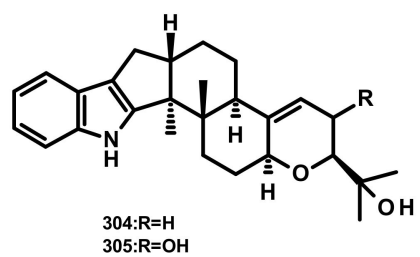

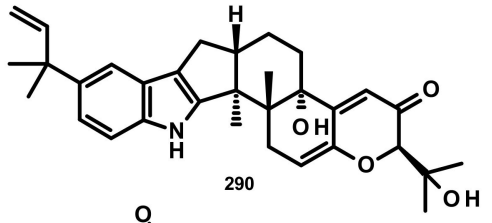
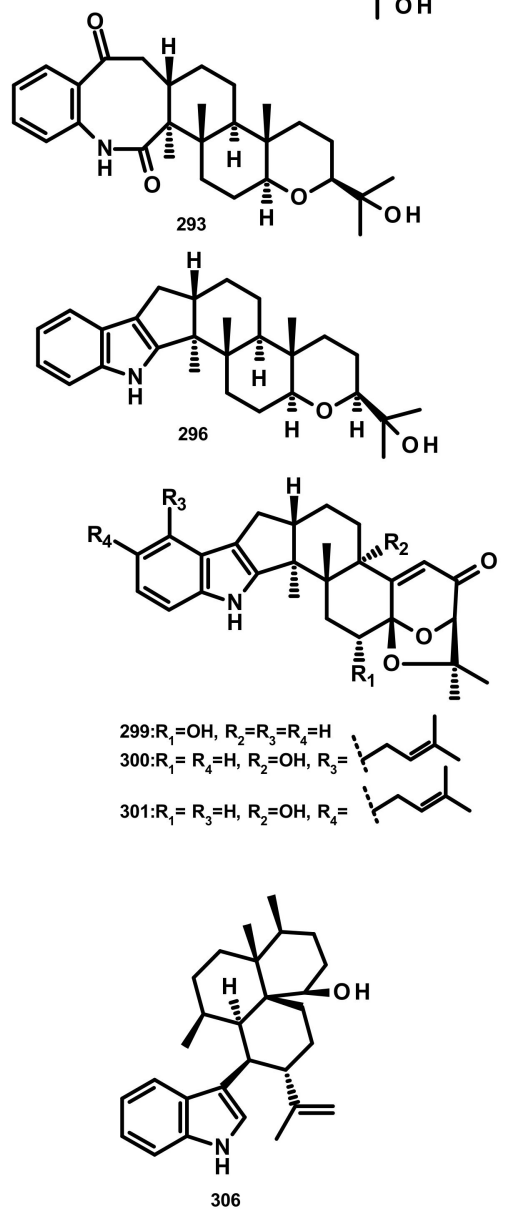

Figure 27. Chemical structures 289-306.

Penicindopene A (307) (Figure 28), an indole-bicylic diterpene, was isolated from the culture extract of Penicillium sp. YPCMAC1, obtained from the deep-sea water at a depth of $4500 \mathrm{~m}$ of the Yap Trench in the West Pacific Ocean. Compound 307 displayed a moderate antitumour activity against A549 and HeLa cell lines with $\mathrm{IC}_{50}$ values of 15.2 and $20.5 \mu \mathrm{M}$, respectively [84]. Two indole-tricyclic diterpenes, penijanthines $C$ (308) and D (309) (Figure 28), were reported together with 305 and 7-hydroxy-13-dehydroxypaxilline (310) (Figure 28), from the marine-derived fungus Penicillium janthinellum, which was isolated from a marine sediment collected from the Bohai Sea. Compounds 305, 308, 309 and 310 displayed significant growth inhibitory activity against Gram-negative halophilic pathogenic bacteria $V$. anguillarum, V. parahemolyticus, and V. alginolyticus with MIC values ranging from 3.1 to $50.0 \mu \mathrm{M}$ [85] (Figure 28). 


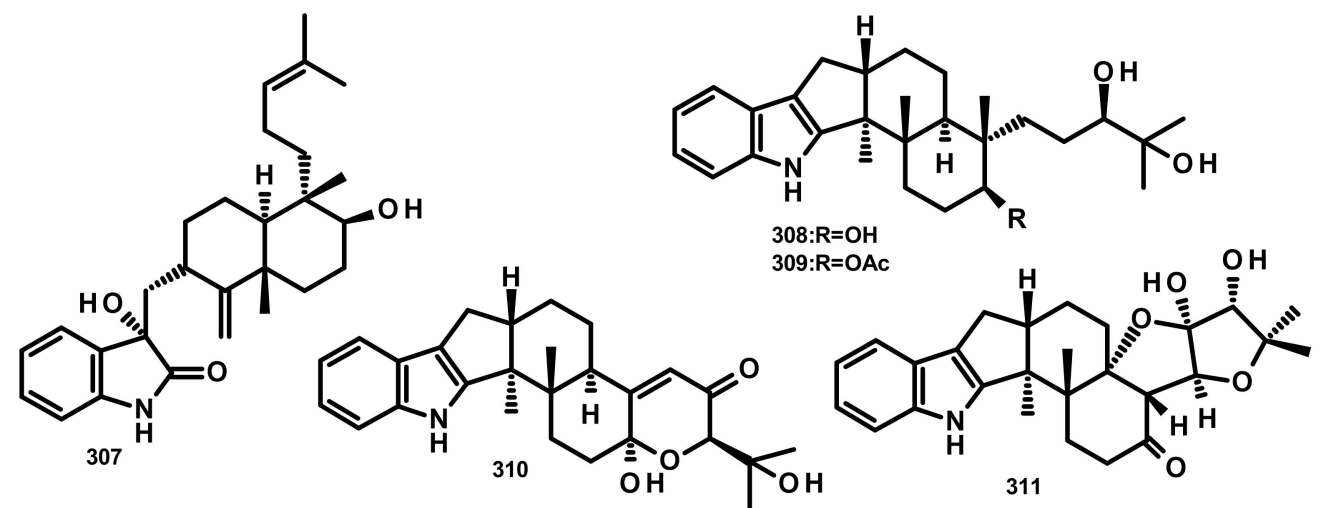<smiles>CC12c3[nH]c4ccccc4c3C[C@@H]1CC[C@H]1C3=CC(=O)CO[C@@H]3CC[C@@]12C</smiles>

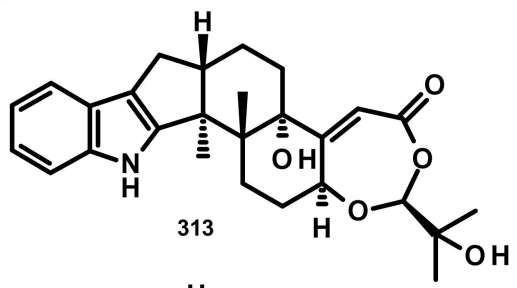

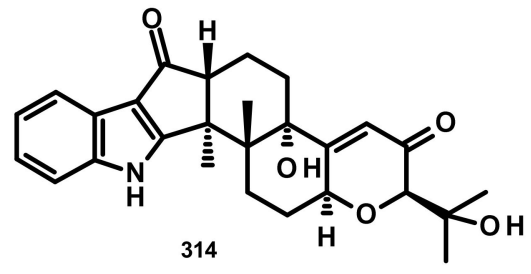

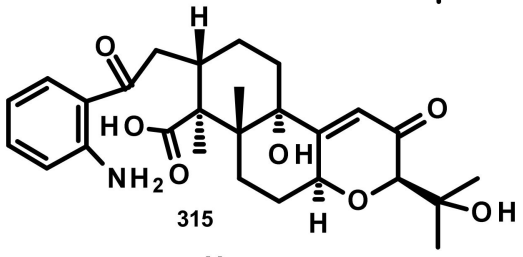<smiles>CC(C)(O)C1O[C@]2(O)CC[C@]3(C)C(=CC[C@@H]4Cc5c([nH]c6ccccc56)[C@]3(C)C4)C2=CC1=O</smiles><smiles>CC(C)(O)[C@@H]1CC[C@]2(O)[C@H]3CC[C@H]4Cc5c([nH]c6ccccc56)[C@]4(C)[C@]3(C)CC[C@H]2O1</smiles>

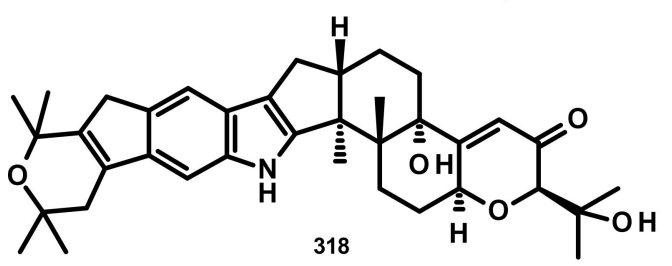

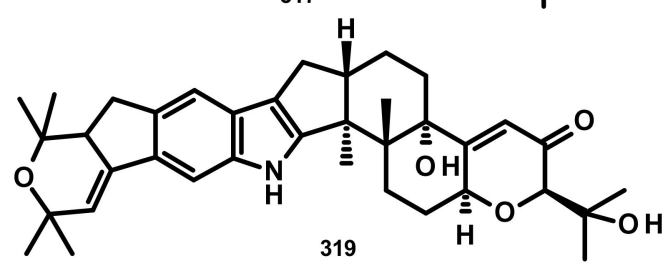

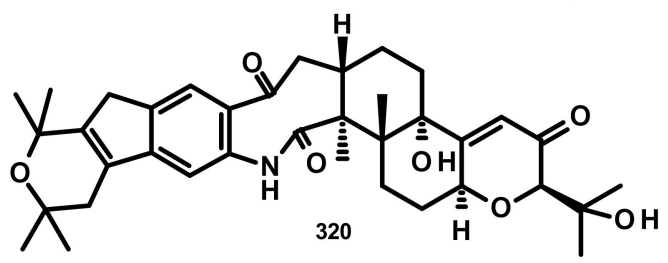

Figure 28. Chemical structures of 307-320.

Previously unreported penerpenes E-I (311-315) (Figure 28), along with the known congeners including 293, 304, 7-hydroxypaxilline-13-ene (316), paspaline B (317), pyrapaxilline (318), shearinine B (319) and shearinine P (320) (Figure 28), were isolated from the marine-derived fungus Penicillium sp. KFD28 which was obtained from a bivalve mollusc, Meretrix lusoria, collected from Haikou Bay. Compounds 311, 312, 314 and 316 displayed moderate protein tyrosine phosphatase 1B (PTP1B) inhibitory activity with $\mathrm{IC}_{50}$ values of $14,27,23$, and $13 \mu \mathrm{M}$, respectively [86]. 


\section{Conclusions and Prospects}

The marine world represents the largest and most diverse ecosystem on earth. Since 1950's, marine natural products chemists have raised the prospects of marine natural products (MNPs) as a great potential and renewable pipelines for compounds of a huge interest in pharmaceutical, nutraceutical and cosmetic industries. Marine microorganisms have become increasingly attractive as sources of compounds with unique structural features and unprecedented pharmacological activities. Marine-derived fungi represent an important source of MNPs due to their variable habitats from the tropics to the polar regions, from the surface to the seafloor and even at such extreme temperature and pressure as in a hydrothermal vent. Moreover, marine-derived fungi are also a prolific source of secondary metabolites capable of synthesizing a myriad of chemical classes of compounds. One of the most interesting classes of fungal secondary metabolites is meroterpenoids. According to our literature search over the period of January 2009 to the end of December 2019, 320 marine meroterpenoids have been reported from a myriad of marine-derived fungi from different habitats, many of which possess unique structural features and undescribed biological and pharmacological activities. At present, natural products from marine-derived fungi have not yet attained the status of the compounds produced by other marine organisms in the pharmaceutical industry. However, this is a question of time since many compounds produced by terrestrial fungi have been approved and successfully marketed as antibiotics, anticholesterolemic, among others. Moreover, many compounds have been successfully explored as cosmeceuticals and nutricosmetics whose market is in a marked expansion. Thus, the contribution of MNPs is undoubtedly vital not only for the pharmaceutical industry but also for other health industries, as well as for the preservation of the marine environment. Marine fungi are undoubtedly an important reservoir of a hidden treasure awaiting to be explored. With a rapid advancement of culture techniques, genome mining to uncover biosynthetic gene clusters, extraction processes and molecular techniques for bioassays, marine-derived fungi could become a great potential to provide valuable compounds as leads for drug development to combat many diseases, to maintain our healthy appearance and even for molecular tools to unlock the mechanisms of many rare and incurable diseases. With modern biotechnological processes, marine-derived fungi can be a huge renewable and untapped source of bioactive natural products while keeping the marine environment intact.

Author Contributions: A.K. conceptualized, organized, corrected and revised the manuscript. A.E.-D. carried out the literature search and prepared a draft of the manuscript. D.K. participated in a manuscript preparation and checked the literature. All authors have read and agreed to the published version of the manuscript.

Funding: This work was partially supported through national funds provided by FCT/MCTES-Foundation for Science and Technology from the Minister of Science, Technology and Higher Education (PIDDAC) and European Regional Development Fund (ERDF) through the COMPETE-Programa Operacional Factores de Competitividade (POFC) programme, under the projects PTDC/MAR-BIO/4694/2014 (reference POCI-01-0145-FEDER-016790), POCI-01-0145-FEDER-028736 and by national fund through FCT-Foundation for Sciences and Technology within the scope of UIDB/04423/2020 and UIDP/04423/2020.

Acknowledgments: Amr El-Demerdash thanks the John Innes Centre, Department of Metabolic Biology of the Norwich Research Park, UK, for a postdoctoral scholarship. Decha Kumla thanks the Alfabet Project of the Erasmus Mundus for a PhD scholarship to the University of Porto.

Conflicts of Interest: The authors declare no conflict of interest.

\section{References}

1. Matsuda, Y.; Abe, I. Biosynthesis of fungal meroterpenoids. Nat. Prod. Rep. 2016, 33, 26-53. [CrossRef]

2. Peng, X.; Qiu, M. Meroterpenoids from Ganoderma species: A Review of Last Five Years. Nat. Prod. Bioprospect. 2018, 8, 137-149. [CrossRef]

3. Menna, M.; Imperatore, C.; D'Aniello, F.; Aiello, A. Meroterpenes from marine invertebrates: Structures, occurrence, and ecological implications. Mar. Drugs 2013, 11, 1602-1643. [CrossRef]

4. Geris, R.; Simpson, T.J. Meroterpenoids produced by fungi. Nat. Prod. Rep. 2009, 26, 1063-1094. [CrossRef] [PubMed] 
5. Hu, Y.; Legako, A.G.; Espindola, A.P.D.M.; MacMillan, J.B. Erythrolic acids A-E, meroterpenoids from a marine-derived Erythrobacter sp. J. Org. Chem. 2012, 77, 3401-3407. [CrossRef] [PubMed]

6. Hu, Y.; MacMillan, J. Biologically active meroterpenoids from Erythrobacter sp. Planta Med. 2012, 78, PI2. [CrossRef]

7. Bo, G. Giuseppe Brotzu and the discovery of cephalosporins. Clin. Microbiol. Infect. 2000, 6, 6-8. [CrossRef]

8. Fenical, W.; Jensen, P.R. Marine microorganisms: A new biomedical resource. In Marine Biotechnology; Attaway, D.H., Zaborsky, O.R., Eds.; Plenum Press: New York, NY, USA, 1993; Volume 1, pp. 419-457, ISBN 978-1-4899-2391-2.

9. Bugni, T.S.; Ireland, C.M. Marine-derived fungi: A chemically and biologically diverse group of microorganisms. Nat. Prod. Rep. 2004, 21, 143-163. [CrossRef] [PubMed]

10. Rateb, M.E.; Ebel, R. Secondary metabolites of fungi from marine habitats. Nat. Prod. Rep. 2011, 28, $290-344$. [CrossRef]

11. Petersen, L.-E.; Kellermann, M.Y.; Schupp, P.J. Secondary metabolites of marine microbes: From natural products chemistry to chemical ecology. In YOUMARES 9-The Oceans: Our Research, Our Future; Jungblut, S., Liebich, V., Bode-Dalby, M., Eds.; Springer International Publishing: Cham, Switzerland, 2020; pp. 159-180, ISBN 987-3-030-20388-7.

12. Fisch, K.M.; Bohm, V.; Wright, A.D.; Konig, G.M. Antioxidative meroterpenoids from the brown alga Cystoseira crinita. J. Nat. Prod. 2003, 66, 968-975. [CrossRef]

13. Cueto, M.; MacMillan, J.B.; Jensen, P.R.; Fenical, W. Tropolactones A-D, four meroterpenoids from a marine-derived fungus of the genus Aspergillus. Phytochemistry 2006, 67, 1826-1831. [CrossRef] [PubMed]

14. Wu, C.Z.; Cai, X.F.; Dat, N.T.; Hong, S.S.; Han, A.R.; Seo, E.K.; Hwang, B.Y.; Nan, J.X.; Lee, D.; Lee, J.J. Bisbakuchiols A and B, novel dimeric meroterpenoids from Psoralea corylifolia. Tetehedon Lett. 2007, 48, 8861-8864. [CrossRef]

15. Jagels, A.; Hövelmann, Y.; Zielinski, A.; Esselen, M.; Köhler, J.; Hübner, F.; Humpf, H.-U. Stachybotrychromenes A-C: Novel cytotoxic meroterpenoids from Stachybotrys sp. Mycotoxin Res. 2018, 34, 179-185. [CrossRef] [PubMed]

16. Kanokmedhakul, K.; Kanokmedhakul, S.; Suwannatrai, R.; Soytong, K.; Prabpai, S.; Kongsaeree, P. Bioactive meroterpenoids and alkaloids from the fungus Eurotium chevalieri. Tetrahedron 2011, 67, 5461-5468. [CrossRef]

17. Mamemura, T.; Tanaka, N.; Shibazaki, A.; Gonoi, T.; Kobayashi, J. Yojironins A-D, meroterpenoids and prenylated acylphloroglucinols from Hypericum yojiroanum. Tetrahedron Lett. 2011, 52, 3575-3578. [CrossRef]

18. Peng, J.X.; Zhang, X.M.; Wang, W.; Zhu, T.J.; Gu, Q.Q.; Li, D.H. Austalides S-U, New meroterpenoids from the sponge-derived fungus Aspergillus aureolatus HDN14-107. Mar. Drugs 2016, 14. [CrossRef]

19. Cao, X.; Shi, Y.T.; Wu, X.D.; Wang, K.W.; Huang, S.H.; Sun, H.X.; Dickschat, J.S.; Wu, B. Talaromyolides A-D and talaromytin: Polycyclic meroterpenoids from the fungus Talaromyces sp. CX11. Org. Lett. 2019, 21, 6539-6542. [CrossRef]

20. Chen, S.H.; Ding, M.; Liu, W.Y.; Huang, X.S.; Liu, Z.M.; Lu, Y.J.; Liu, H.J.; She, Z.G. Anti-inflammatory meroterpenoids from the mangrove endophytic fungus Talaromyces amestolkiae YX1. Phytochemistry 2018, 146, 8-15. [CrossRef]

21. Long, Y.H.; Cui, H.; Liu, X.L.; Xiao, Z.E.; Wen, S.T.; She, Z.G.; Huang, X.S. Acetylcholinesterase inhibitory meroterpenoid from a mangrove endophytic fungus Aspergillus sp 16-5c. Molecules 2017, 22. [CrossRef]

22. Fraser, J.A.; Lambert, L.K.; Pierens, G.K.; Bernhardt, P.V.; Garson, M.J. Secondary metabolites of the sponge-derived fungus Acremonium persicinum. J. Nat. Prod. 2013, 76, 1432-1440. [CrossRef]

23. Zhang, Q.; Yang, B.; Li, F.; Liu, M.; Lin, S.; Wang, J.; Xue, Y.; Zhu, H.; Sun, W.; Hu, Z. Mycophenolic acid derivatives with immunosuppressive activity from the coral-derived fungus Penicillium bialowiezense. Mar. Drugs 2018, 16, 230. [CrossRef] [PubMed]

24. Elissawy, A.M.; Ebada, S.S.; Ashour, M.L.; Ozkaya, F.C.; Ebrahim, W.; Singab, A.B.; Proksch, P. Spiroarthrinols $\mathrm{A}$ and $\mathrm{B}$, two novel meroterpenoids isolated from the sponge-derived fungus Arthrinium sp. Phytochem. Lett. 2017, 20, 246-251. [CrossRef]

25. Alves, A.J.S.; Pereira, J.A.; Dethoup, T.; Cravo, S.; Mistry, S.; Silva, A.M.S.; Pinto, M.M.M.; Kijjoa, A. A new meroterpene, a new benzofuran derivative and other constituents from cultures of the marine sponge-associated fungus Acremonium persicinum KUFA 1007 and their anticholinesterase activities. Mar. Drugs 2019, 17, 379. [CrossRef] [PubMed] 
26. Mei, W.-L.; Zheng, B.; Zhao, Y.-X.; Zhong, H.-M.; Chen, X.-L.W.; Zeng, Y.-B.; Dong, W.-H.; Huang, J.-L.; Proksch, P.; Dai, H.-F. Meroterpenes from endophytic fungus A1 of mangrove plant Scyphiphora hydrophyllacea. Mar. Drugs 2012, 10, 1993-2001. [CrossRef] [PubMed]

27. Bai, Z.Q.; Lin, X.P.; Wang, J.F.; Zhou, X.F.; Liu, J.; Yang, B.; Yang, X.W.; Liao, S.R.; Wang, L.S.; Liu, Y.H. New meroterpenoids from the endophytic fungus Aspergillus flavipes AIL8 derived from the mangrove plant Acanthus ilicifolius. Mar. Drugs 2015, 13, 237-248. [CrossRef] [PubMed]

28. Zhang, G.J.; Wu, G.W.; Zhu, T.J.; Kurtan, T.; Mandi, A.; Jiao, J.Y.; Li, J.; Qi, X.; Gu, Q.Q.; Li, D.H. Meroterpenoids with diverse ring systems from the sponge-associated fungus Alternaria sp. JJY-32. J. Nat. Prod. 2013, 76, 1946-1957. [CrossRef]

29. Sun, X.H.; Kong, X.L.; Gao, H.Q.; Zhu, T.J.; Wu, G.W.; Gu, Q.Q.; Li, D.H. Two new meroterpenoids produced by the endophytic fungus Penicillium sp SXH-65. Arch. Pharm. Res. 2014, 37, 978-982. [CrossRef]

30. He, W.J.; Zhou, X.J.; Qin, X.C.; Mai, Y.X.; Lin, X.P.; Liao, S.R.; Yang, B.; Zhang, T.Y.; Tu, Z.C.; Wang, J.F. Quinone/hydroquinone meroterpenoids with antitubercular and cytotoxic activities produced by the sponge-derived fungus Gliomastix sp. ZSDS1-F7. Nat. Prod. Res. 2017, 31, 604-609. [CrossRef]

31. Kong, F.D.; Ma, Q.Y.; Huang, S.Z.; Wang, P.; Wang, J.F.; Zhou, L.M.; Yuan, J.Z.; Dai, H.F.; Zhao, Y.X. Chrodrimanins K-N and related meroterpenoids from the fungus Penicillium sp. SCS-KFD09 isolated from a marine worm, Sipunculus nudus. J. Nat. Prod. 2017, 80, 1039-1047. [CrossRef]

32. Wang, W.; Lee, J.; Kim, K.-J.; Sung, Y.; Park, K.-H.; Oh, E.; Park, C.; Son, Y.-J.; Kang, H. Austalides, osteoclast differentiation inhibitors from a marine-derived strain of the fungus Penicillium rudallense. J. Nat. Prod. 2019, 82, 3083-3088. [CrossRef]

33. Cheng, Z.; Xu, W.; Liu, L.; Li, S.; Yuan, W.; Luo, Z.; Zhang, J.; Cheng, Y.; Li, Q. Peniginsengins B-E, new farnesylcyclohexenones from the deep sea-derived fungus Penicillium sp. YPGA11. Mar. Drugs 2018, 16, 358. [CrossRef]

34. Fang, S.-T.; Miao, F.-P.; Liu, X.-H.; Song, Y.-P.; Ji, N.-Y. Two new tricycloalternarene acids from the marine-derived fungus Alternaria alternata ICD5-11. Phytochem. Lett. 2018, 23, 185-188. [CrossRef]

35. Yurchenko, A.N.; Smetanina, O.F.; Kalinovsky, A.I.; Pivkin, M.V.; Dmitrenok, P.S.; Kuznetsova, T.A. A new meroterpenoid from the marine fungus Aspergillus versicolor (Vuill.) Tirab. Russ. Chem. Bull. 2010, 59, 852-856. [CrossRef]

36. Li, H.Q.; Sun, W.G.; Deng, M.Y.; Qi, C.X.; Chen, C.M.; Zhu, H.C.; Luo, Z.W.; Wang, J.P.; Xue, Y.B.; Zhang, Y.H. Asperversins $A$ and $B$, two novel meroterpenoids with an unusual 5/6/6/6 ring from the marine-derived fungus Aspergillus versicolor. Mar. Drugs 2018, 16, 177. [CrossRef] [PubMed]

37. Huang, X.; Sun, X.; Ding, B.; Lin, M.; Liu, L.; Huang, H.; She, Z. A New anti-acetylcholinesterase $\alpha$-pyrone meroterpene, arigsugacin I, from mangrove endophytic fungus Penicillium sp. sk5GW1L of Kandelia candel. Planta Med. 2013, 79, 1572-1575. [CrossRef] [PubMed]

38. Prompanya, C.; Dethoup, T.; Bessa, L.J.; Pinto, M.M.M.; Gales, L.; Costa, P.M.; Silva, A.M.S.; Kijjoa, A. New isocoumarin derivatives and meroterpenoids from the marine sponge-associated fungus Aspergillus similanensis sp. nov. KUFA 0013. Mar. Drugs 2014, 12, 5160-5173. [CrossRef] [PubMed]

39. Ding, B.; Wang, Z.Y.; Huang, X.S.; Liu, Y.Y.; Chen, W.R.; She, Z.G. Bioactive $\alpha$-pyrone meroterpenoids from mangrove endophytic fungus Penicillium sp. Nat. Prod. Res. 2016, 30, 2805-2812. [CrossRef]

40. Ding, Z.; Zhang, L.; Fu, J.; Che, Q.; Li, D.; Gu, Q.; Zhu, T. Phenylpyropenes E and F: New meroterpenes from the marine-derived fungus Penicillium concentricum ZLQ-69. J. Antibiot. 2015, 68, 748-751. [CrossRef]

41. Prompanya, C.; Fernandes, C.; Cravo, S.; Pinto, M.M.M.; Dethoup, T.; Silva, A.M.S.; Kijjoa, A. A new cyclic hexapeptide and a new isocoumarin derivative from the marine sponge-associated fungus Aspergillus similanensis KUFA 0013. Mar. Drugs 2015, 13, 1432-1450. [CrossRef]

42. Cao, Q.-X.; Wei, J.-H.; Deng, R.; Feng, G.-K.; Zhu, X.-F.; Lan, W.-J.; Li, H.-J. Two new pyripyropenes from the marine fungus Fusarium lateritium 2016F18-1. Chem. Biodivers. 2017, 14. [CrossRef]

43. Lan, W.-J.; Fu, S.-J.; Xu, M.-Y.; Liang, W.-L.; Lam, C.-K.; Zhong, G.-H.; Xu, J.; Yang, D.-P.; Li, H.-J. Five new cytotoxic metabolites from the marine fungus Neosartorya pseudofischeri. Mar. Drugs 2016, 14, 18. [CrossRef] [PubMed]

44. Liao, L.J.; Lee, J.H.; You, M.J.; Choi, T.J.; Park, W.; Lee, S.K.; Oh, D.C.; Oh, K.B.; Shin, J. Penicillipyrones A and B, meroterpenoids from a marine-derived Penicillium sp. fungus. J. Nat. Prod. 2014, 77, 406-410. [CrossRef] [PubMed] 
45. Mohamed, I.E.; Gross, H.; Pontius, A.; Kehraus, S.; Krick, A.; Kelter, G.; Maier, A.; Fiebig, H.-H.; König, G.M. Epoxyphomalin A and B, prenylated polyketides with potent cytotoxicity from the marine-derived fungus Phoma sp. Org. Lett. 2009, 11, 5014-5017. [CrossRef] [PubMed]

46. Mohamed, I.E.; Kehraus, S.; Krick, A.; König, G.M.; Kelter, G.; Maier, A.; Fiebig, H.-H.; Kalesse, M.; Malek, N.P.; Gross, H. Mode of action of epoxyphomalins A and B and characterization of related metabolites from the marine-derived fungus Paraconiothyrium sp. J. Nat. Prod. 2010, 73, 2053-2056. [CrossRef] [PubMed]

47. Liu, H.; Li, X.M.; Liu, Y.; Zhang, P.; Wang, J.N.; Wang, B.G. Chermesins A-D: Meroterpenoids with a drimane-type spirosesquiterpene skeleton from the marine algal-derived endophytic fungus Penicillium chermesinum EN-480. J. Nat. Prod. 2016, 79, 806-811. [CrossRef] [PubMed]

48. Liu, D.; Li, Y.; Li, X.D.; Cheng, Z.B.; Huang, J.; Proksch, P.; Lin, W.H. Chartarolides A-C, novel meroterpenoids with antitumor activities. Tetrahedron Lett. 2017, 58, 1826-1829. [CrossRef]

49. Zhou, Y.; Mándi, A.; Debbab, A.; Wray, V.; Schulz, B.; Müller, W.E.G.; Lin, W.; Proksch, P.; Kurtán, T.; Aly, A.H. New austalides from the sponge-associated fungus Aspergillus sp. Eur. J. Org. Chem. 2011, 6009-6019. [CrossRef]

50. Zhuravleva, O.I.; Sobolevskaya, M.P.; Leshchenko, E.V.; Kirichuk, N.N.; Denisenko, V.A.; Dmitrenok, P.S.; Dyshlovoy, S.A.; Zakharenko, A.M.; Kim, N.Y.; Afiyatullov, S.S. Meroterpenoids from the alga-derived fungi Penicillium thomii Maire and Penicillium lividum Westling. J. Nat. Prod. 2014, 77, 1390-1395. [CrossRef]

51. Huang, G.L.; Zhou, X.M.; Bai, M.; Liu, Y.X.; Zhao, Y.L.; Luo, Y.P.; Niu, Y.Y.; Zheng, C.J.; Chen, G.Y. Dihydroisocoumarins from the mangrove-derived fungus Penicillium citrinum. Mar. Drugs 2016, 14, 177. [CrossRef]

52. Arunpanichlert, J.; Rukachaisirikul, V.; Phongpaichit, S.; Supaphon, O.; Sakayaroj, J. Meroterpenoid, isocoumarin, and phenol derivatives from the seagrass-derived fungus Pestalotiopsis sp. PSU-ES 194. Tetrahedron 2015, 71, 882-888. [CrossRef]

53. Liu, Z.M.; Liu, H.J.; Chen, Y.; She, Z.G. A new anti-inflammatory meroterpenoid from the fungus Aspergillus terreus H010. Nat. Prod. Res. 2018, 32, 2652-2656. [CrossRef] [PubMed]

54. Park, J.S.; Quang, T.H.; Yoon, C.S.; Kim, H.J.; Sohn, J.H.; Oh, H. Furanoaustinol and 7-acetoxydehydroaustinol: New meroterpenoids from a marine-derived fungal strain Penicillium sp. SF-5497. J. Antibiot. 2018, 71, 557-563. [CrossRef] [PubMed]

55. Bai, M.; Zheng, C.J.; Huang, G.L.; Mei, R.Q.; Wang, B.; Luo, Y.P.; Zheng, C.; Niu, Z.G.; Chen, G.Y. Bioactive meroterpenoids and isocoumarins from the mangrove derived fungus Penicillium sp. TGM112. J. Nat. Prod. 2019, 82, 1155-1164. [CrossRef] [PubMed]

56. Hwang, J.-Y.; You, M.J.; Oh, D.-C.; Oh, K.-B.; Shin, J. New meroterpenoids from a Penicillium sp. Fungus. Nat. Prod. Sci. 2018, 24, 253-258. [CrossRef]

57. Wen, H.; Yang, X.; Liu, Q.; Li, S.; Li, Q.; Zang, Y.; Chen, C.; Wang, J.; Zhu, H.; Zhang, Y. Structurally diverse meroterpenoids from a marine-derived Aspergillus sp. fungus. J. Nat. Prod. 2020, 83, 99-104. [CrossRef] [PubMed]

58. Zhang, J.P.; Wu, Y.F.; Yuan, B.C.; Liu, D.; Zhu, K.; Huang, J.; Proksch, P.; Lin, W.H. DMOA-based meroterpenoids with diverse scaffolds from the sponge-associated fungus Penicillium brasilianum. Tetrahedron 2019, 75, 2193-2205. [CrossRef]

59. Zhang, Y.; Li, X.-M.; Shang, Z.; Li, C.-S.; Ji, N.-Y.; Wang, B.-G. Meroterpenoid and diphenyl ether derivatives from Penicillium sp. MA-37, a fungus isolated from marine mangrove rhizospheric soil. J. Nat. Prod. 2012, 75, 1888-1895. [CrossRef]

60. Li, J.; Yang, X.; Lin, Y.; Yuan, J.; Lu, Y.; Zhu, X.; Li, J.; Li, M.; Lin, Y.; He, J. Meroterpenes and azaphilones from marine mangrove endophytic fungus Penicillium 303\#. Fitoterapia 2014, 97, 241-246. [CrossRef]

61. Hoang, T.P.T.; Roullier, C.; Boumard, M.C.; du Pont, T.R.; Nazih, H.; Gallard, J.F.; Pouchus, Y.F.; Beniddir, M.A.; Grovel, O. Metabolomics-driven discovery of meroterpenoids from a mussel-derived Penicillium ubiquetum. J. Nat. Prod. 2018, 81, 2501-2511. [CrossRef]

62. Zhang, J.P.; Yuan, B.C.; Liu, D.; Gao, S.; Proksch, P.; Lin, W.H. Brasilianoids A-F, new meroterpenoids from the sponge-associated fungus Penicillium brasilianum. Front. Chem. 2018, 6, 314. [CrossRef]

63. Gu, B.B.; Wu, W.; Liu, L.Y.; Tang, J.; Zeng, Y.J.; Wang, S.P.; Sun, F.; Li, L.; Yang, F.; Lin, H.W. 3,5-Dimethylorsellinic acid derived meroterpenoids from Eupenicillium sp. 6A-9, a Fungus Isolated from the marine sponge Plakortis simplex. Eur. J. Org. Chem. 2018, 48-59. [CrossRef] 
64. Park, J.-S.; Quang, T.H.; Thi Thanh Ngan, N.; Sohn, J.H.; Oh, H. New preaustinoids from a marine-derived fungal strain Penicillium sp. SF-5497 and their inhibitory effects against PTP1B activity. J. Antibiot. 2019, 72, 629-633. [CrossRef] [PubMed]

65. López-Gresa, M.P.; Cabedo, N.; González-Mas, M.C.; Ciavatta, M.L.; Avila, C.; Primo, J. Terretonins E and F, inhibitors of the mitochondrial respiratory chain from the marine-derived fungus Aspergillus insuetus. J. Nat. Prod. 2009, 72, 1348-1351. [CrossRef] [PubMed]

66. Fukuda, T.; Kurihara, Y.; Kanamoto, A.; Tomoda, H. Terretonin G, a new sesterterpenoid antibiotic from marine-derived Aspergillus sp. OPMF00272. J. Antibiot. 2014, 67, 593-595. [CrossRef] [PubMed]

67. Li, H.L.; Li, X.M.; Li, X.; Yang, S.Q.; Wang, B.G. Structure, absolute configuration and biological evaluation of polyoxygenated meroterpenoids from the marine algal-derived Aspergillus terreus EN-539. Phytochem. Lett. 2019, 32, 138-142. [CrossRef]

68. Hamed, A.; Abdel-Razek, A.S.; Omran, D.A.; El-Metwally, M.M.; El-Hosari, D.G.; Frese, M.; Soliman, H.S.M.; Sewald, N.; Shaaban, M. Terretonin O: A new meroterpenoid from Aspergillus terreus. Nat. Prod. Res. 2020, 34, 965-974. [CrossRef]

69. Wu, C.-J.; Cui, X.; Xiong, B.; Yang, M.-S.; Zhang, Y.-X.; Liu, X.-M. Terretonin D1, a new meroterpenoid from marine-derived Aspergillus terreus ML-44. Nat. Prod. Res. 2019, 33, 2262-2265. [CrossRef]

70. Cheng, Z.B.; Xu, W.; Wang, Y.Y.; Bai, S.Y.; Liu, L.J.; Luo, Z.H.; Yuan, W.J.; Li, Q. Two new meroterpenoids and two new monoterpenoids from the deep sea-derived fungus Penicillium sp. YPGA11. Fitoterapia 2019, 133, 120-124. [CrossRef]

71. Xie, C.-L.; Xia, J.-M.; Lin, T.; Lin, Y.-J.; Lin, Y.-K.; Xia, M.-L.; Chen, H.-F.; Luo, Z.-H.; Shao, Z.-Z.; Yang, X.-W. Andrastone A From the deep-sea-derived fungus Penicillium allii-sativi acts as an inducer of caspase and RXR $\alpha$-dependent apoptosis. Front. Chem. 2019, 7, 692. [CrossRef]

72. Li, H.-L.; Xu, R.; Li, X.-M.; Yang, S.-Q.; Meng, L.-H.; Wang, B.-G. Simpterpenoid A, a meroterpenoid with a highly functionalized cyclohexadiene moiety featuring gem-propane-1,2-dione and methylformate groups, from the mangrove-derived Penicillium simplicissimum MA-332. Org. Lett. 2018, 20, 1465-1468. [CrossRef]

73. Wang, Y.Z.; Qi, S.; Zhan, Y.; Zhang, N.W.; Wu, A.A.; Gui, F.; Guo, K.; Yang, Y.R.; Cao, S.G.; Hu, Z.Y. Aspertetranones A-D, putative meroterpenoids from the marine algal-associated fungus Aspergillus sp. ZL0-1b14. J. Nat. Prod. 2015, 78, 2405-2410. [CrossRef]

74. Qi, C.X.; Qiao, Y.B.; Gao, W.X.; Liu, M.T.; Zhou, Q.; Chen, C.M.; Lai, Y.J.; Xue, Y.B.; Zhang, J.W.; Li, D.Y. New 3,5-dimethylorsellinic acid-based meroterpenoids with BACE1 and AchE inhibitory activities from Aspergillus terreus. Org. Biomol. Chem. 2018, 16, 9046-9052. [CrossRef]

75. Eamvijarn, A.; Gomes, N.M.; Dethoup, T.; Buaruang, J.; Manoch, L.; Silva, A.; Pedro, M.; Marini, I.; Roussis, V.; Kijjoa, A. Bioactive meroditerpenes and indole alkaloids from the soil fungus Neosartorya fischeri (KUFC 6344), and the marine-derived fungi Neosartorya laciniosa (KUFC 7896) and Neosartorya tsunodae (KUFC 9213). Tetrahedron 2013, 69, 8583-8591. [CrossRef]

76. Gomes, N.M.; Bessa, L.J.; Buttachon, S.; Costa, P.M.; Buaruang, J.; Dethoup, T.; Silva, A.M.S.; Kijjoa, A. Antibacterial and antibiofilm activities of tryptoquivalines and meroditerpenes isolated from the marine-derived fungi Neosartorya paulistensis, N. laciniosa, N. tsunodae, and the soil fungi N. fischeri and N. siamensis. Mar. Drugs 2014, 12, 822-839. [CrossRef] [PubMed]

77. Zin, W.W.M.; Buttachon, S.; Buaruang, J.; Gales, L.; Pereira, J.A.; Pinto, M.M.M.; Silva, A.M.S.; Kijjoa, A. A new meroditerpene and a new tryptoquivaline analog from the algicolous fungus Neosartorya takakii KUFC 7898. Mar. Drugs 2015, 13, 3776-3790. [CrossRef] [PubMed]

78. Prata-Sena, M.; Ramos, A.A.; Buttachon, S.; Castro-Carvalho, B.; Marques, P.; Dethoup, T.; Kijjoa, A.; Rocha, E. Cytotoxic activity of secondary metabolites from marine-derived fungus Neosartorya siamensis in human cancer cells. Phytother. Res. 2016, 30, 1862-1871. [CrossRef]

79. Hu, Y.; Yang, M.; Zhao, J.; Liao, Z.; Qi, J.; Wang, X.; Jiang, W.; Xia, X. A Meroterpenoid isolated from the fungus Aspergillus sp. Nat. Prod. Comm. 2019, 14,1-3. [CrossRef]

80. Gao, S.-S.; Li, X.-M.; Williams, K.; Proksch, P.; Ji, N.-Y.; Wang, B.-G. Rhizovarins A-F, indole-diterpenes from the mangrove-derived endophytic fungus Mucor irregularis QEN-189. J. Nat. Prod. 2016, 79, 2066-2074. [CrossRef]

81. Sun, K.; Li, Y.; Guo, L.; Wang, Y.; Liu, P.; Zhu, W. Indole diterpenoids and isocoumarin from the fungus, Aspergillus flavus, isolated from the prawn, Penaeus vannamei. Mar. Drugs 2014, 12, 3970-3981. [CrossRef] 
82. Chea, S.; Zhan, Y. Isolation of novel indole diterpenes and dihydrodibenzofuran from the marine fungus Aspergillus sp. J. Pharm. Bioresour. 2014, 11, 39-45. [CrossRef]

83. Hu, X.-Y.; Meng, L.-H.; Li, X.; Yang, S.-Q.; Li, X.-M.; Wang, B.-G. Three new indole diterpenoids from the sea-anemone-derived fungus Penicillium sp. AS-79. Mar. Drugs 2017, 15. [CrossRef] [PubMed]

84. Liu, L.; Xu, W.; Li, S.; Chen, M.; Cheng, Y.; Yuan, W.; Cheng, Z.; Li, Q. Penicindopene A, a new indole diterpene from the deep-sea fungus Penicillium sp. YPCMAC1. Nat. Prod. Res. 2019, 33, 2988-2994. [CrossRef] [PubMed]

85. Guo, X.-C.; Xu, L.-L.; Yang, R.-Y.; Yang, M.-Y.; Hu, L.-D.; Zhu, H.-J.; Cao, F. Anti-Vibrio indole-diterpenoids and C-25 epimeric steroids from the marine-derived fungus Penicillium janthinellum. Front. Chem. 2019, 7, 80. [CrossRef]

86. Zhou, L.-M.; Kong, F.-D.; Fan, P.; Ma, Q.-Y.; Xie, Q.-Y.; Li, J.-H.; Zheng, H.-Z.; Zheng, Z.-H.; Yuan, J.-Z.; Dai, H.-F. Indole-diterpenoids with protein tyrosine phosphatase inhibitory activities from the marine-derived fungus Penicillium sp. KFD28. J. Nat. Prod. 2019, 82, 2638-2644. [CrossRef] [PubMed]

(C) 2020 by the authors. Licensee MDPI, Basel, Switzerland. This article is an open access article distributed under the terms and conditions of the Creative Commons Attribution (CC BY) license (http://creativecommons.org/licenses/by/4.0/). 